Article

\title{
Expression Profiles and Prognostic Value of FABPs in Colorectal Adenocarcinomas
}

\author{
Fidelia Berenice Prayugo ${ }^{1,2,+}$, Tzu-Jen Kao ${ }^{3,4,5,+}$, Gangga Anuraga ${ }^{2,6,7}$, , Hoang Dang Khoa Ta ${ }^{2,6} \mathbb{D}_{\text {, }}$

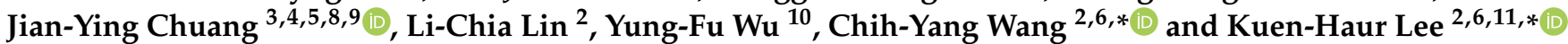

1 International Master/PhD Program in Medicine, College of Medicine, Taipei Medical University, Taipei 11031, Taiwan; m142109005@tmu.edu.tw

2 Graduate Institute of Cancer Biology and Drug Discovery, College of Medical Science and Technology, Taipei Medical University, Taipei 11031, Taiwan; g.anuraga@unipasby.ac.id (G.A.); d621109004@tmu.edu.tw (H.D.K.T.); m654108001@tmu.edu.tw (L.-C.L.)

3 The PhD Program for Neural Regenerative Medicine, Taipei Medical University, Taipei 11031, Taiwan; geokao@tmu.edu.tw (T.-J.K.); chuangcy@tmu.edu.tw (J.-Y.C.)

4 Research Center of Neuroscience, Taipei Medical University, Taipei 11031, Taiwan

5 TMU Research Center of Cancer Translational Medicine, Taipei Medical University, Taipei 11031, Taiwan

6 PhD Program for Cancer Molecular Biology and Drug Discovery, College of Medical Science and Technology, Taipei Medical University and Academia Sinica, Taipei 11031, Taiwan

7 Department of Statistics, Faculty of Science and Technology, Universitas PGRI Adi Buana, Surabaya 60234, East Java, Indonesia

8 Cell Physiology and Molecular Image Research Center, Wan Fang Hospital, Taipei Medical University, Taipei 11031, Taiwan

check for updates

Citation: Prayugo, F.B.; Kao, T.-J.; Anuraga, G.; Ta, H.D.K.; Chuang, J.-Y.; Lin, L.-C.; Wu, Y.-F.; Wang, C.-Y.; Lee, K.-H. Expression Profiles and Prognostic Value of FABPs in Colorectal Adenocarcinomas. Biomedicines 2021, 9, 1460. https:// doi.org/10.3390/biomedicines9101460

Academic Editors: James A. Marrs and Antonio Biondi

Received: 18 August 2021

Accepted: 6 October 2021

Published: 13 October 2021

Publisher's Note: MDPI stays neutra with regard to jurisdictional claims in published maps and institutional affiliations.

Copyright: (c) 2021 by the authors. Licensee MDPI, Basel, Switzerland. This article is an open access article distributed under the terms and conditions of the Creative Commons Attribution (CC BY) license (https:/ / creativecommons.org/licenses/by/ $4.0 /)$.
9 Department of Biomedical Science and Environmental Biology, Kaohsiung Medical University, Kaohsiung 80708, Taiwan

10 National Defense Medical Center, Department of Medical Research, School of Medicine, Tri-Service General Hospital, Taipei 11490, Taiwan; qrince@yahoo.com.tw

11 Cancer Center, Wan Fang Hospital, Taipei Medical University, Taipei 11031, Taiwan

* Correspondence: chihyang@tmu.edu.tw (C.-Y.W.); khlee@tmu.edu.tw (K.-H.L.)

+ These authors contributed equally.

Abstract: Colorectal cancer (CRC) is one of the world's leading causes of cancer-related deaths; thus, it is important to detect it as early as possible. Obesity is thought to be linked to a large rise in the CRC incidence as a result of bad dietary choices, such as a high intake of animal fats. Fatty acid-binding proteins (FABPs) are a set of molecules that coordinate intracellular lipid responses and are highly associated with metabolism and inflammatory pathways. There are nine types of $F A B P$ genes that have been found in mammals, which are FABP1-7, FABP9, and FABP12. Each FABP gene has its own roles in different organs of the body; hence, each one has different expression levels in different cancers. The roles of FABP family genes in the development of CRC are still poorly understood. We used a bioinformatics approach to examine $F A B P$ family gene expression profiles using the Oncomine, GEPIA, PrognoScan, STRING, cBioPortal, MetaCore, and TIMER platforms. Results showed that the FABP6 messenger $(\mathrm{m}) \mathrm{RNA}$ level is overexpressed in CRC cells compared to normal cells. The overexpression of FABP 6 was found to be related to poor prognosis in CRC patients' overall survival. The immunohistochemical results in the Human Protein Atlas showed that FABP1 and FABP6 exhibited strong staining in CRC tissues. An enrichment analysis showed that high expression of FABP6 was significantly correlated with the role of microRNAs in cell proliferation in the development of CRC through the insulin-like growth factor (IGF) signaling pathway. FABP6 functions as an intracellular bile-acid transporter in the ileal epithelium. We looked at FABP6 expression in CRC since bile acids are important in the carcinogenesis of CRC. In conclusion, high FABP6 expression is expected to be a potential biomarker for detecting CRC at the early stage.

Keywords: $F A B P$ family genes; colorectal cancer; FABP6; bioinformatics; prognosis 


\section{Introduction}

Colorectal cancer (CRC) is the third most prevalent malignant tumor in the world and the second largest cause of cancer-related deaths. In 2020, there were 1,148,515 and 732,210 new instances of colon and rectal cancers reported worldwide, respectively, and it is anticipated that more than half of colon and rectal cancer patients will die from this condition [1]. The large rise in CRC incidence in both industrialized and developing nations is thought to be linked to population aging, bad dietary choices (e.g., excessive animal fat intake and insufficient cellulose intake), lack of physical activity, obesity, and smoking [2].

Fatty-acid binding proteins (FABPs) are a class of molecules that help cells organize their lipid responses, and they are also involved in metabolic and inflammatory processes [3]. The $F A B P$ genes family encodes transcription factors that binds free FAs, cholesterol, and retinoids [4,5]. Some FABP polymorphisms have been linked to lipid metabolism problems and the onset of atherosclerosis, such that FABP levels in the blood are utilized as indicators of tissue injury [6]. Since the discovery of 12 different forms of FABP (FABP1-12), nine of them (FABP1-FABP9) have been verified to be expressed in humans [7]. According to the available literature, FABPs are expressed differently in various kinds of cancer or different cell lines of the same disease [8]. In a broader context, FABPs are lipid chaperones that transport and regulate the biological activities of lipids. Variations in $F A B P$ expression may contribute to tumor development in humans throughout tumor progression. FABP3 [9] in gastric cancer, FABP5 [10] and FABP9 in prostate cancer [11], and $F A B P 7$ in clear-cell renal cell carcinoma [12] have recently been discovered to be diagnostic markers and/or novel therapeutic targets in various cancers.

FABP6 is a bile-acid intracellular transporter in ileal epithelial cells, which supports catalytic cholesterol and metabolism; it is also known as ileal bile-acid-binding protein (I-BABP) and gastrotropine. Bile-acid concentrations, particularly secondary bile acids, are known to be higher in colon adenomas, whereas bile acids promote enhanced $F A B P 6$ expression in colon cancer cell lines in vitro [13]. Fujii et al. found that FABP6 expression was due to bile-acid exposure in a colon cancer cell line [14]. Excess bile acids, especially secondary bile acids, which enter epithelial cells at variable quantities, cause apoptosis and DNA damage, resulting in genetic changes in the colonic epithelium [15]. Furthermore, unusually high bile-acid levels, which connect the intestinal microbiota with the liver and intestinal metabolism, have a substantial detrimental influence on the colonic mucosa, hastening the course of CRC $[16,17]$. In the early stage of CRC, FABP6 was recognized as an overexpressed gene [18]. It is important to design appropriate and efficient early diagnoses and new therapeutic targets. Thus, it is crucial to detect new biomarkers which can provide a fresh understanding of the molecular abnormalities that lead to CRC. Although many researchers have worked hard to understand the mechanisms of FABP6 in CRC regulation, more research is needed [19-21].

In our study, we performed multi-omics analyses to investigate the expression of $F A B P$ genes in human $C R C$. Expression, mutation, and alteration of the $F A B P$ genes were evaluated using the Oncomine, CCLE, GEPIA, and cBioPortal platforms, and the correlation between these $F A B P$ members and clinical outcomes in CRC were examined using PrognoScan and the Human Protein Atlas database analyses [22-27]. The protein-protein interactions (PPIs) between each FABP family member and its predicted functional partner were explored using STRING, whereas we used the TIMER database to identify potential biomarkers in immune infiltration. Additionally, the genes commonly correlated with the $F A B P$ genes were categorized in key pathways related to the tumorigenesis of CRC and analyzed using MetaCore [28-32]. The present study suggests the prognostic value of the FABP6 gene expression and its associated pathways in human CRC. Therefore, $F A B P 6$ is expected to be a candidate biomarker in the diagnosis and prognosis of colorectal adenocarcinomas (COADs). 


\section{Materials and Methods}

\subsection{Data Collection}

mRNA sequencing data, molecular categories, immunohistochemistry (IHC) staining data, and clinical information of colorectal cancer patients and other cancer types were obtained from the TCGA COAD and READ databases (https://tcga-data.nci.nih.gov/, accessed on 14 May 2021), Human Protein Atlas (https:/ / www.proteinatlas.org/, accessed on 14 May 2021), and GEPIA (http:/ / gepia.cancer-pku.cn/index.html, accessed on 14 May 2021), respectively. The expression pattern of normal colon tissues and tumor tissues was acquired from the TCGA database. The STRING (https:/ / www.string-db.org/, accessed on 14 May 2021) database and MetaCore (https://portal.genego.com/, accessed on 14 May 2021) platform were used to construct the PPI network and enrichment pathway. We obtained the immune cell content file of the TCGA sample from the TIMER database (https:/ / cistrome.shinyapps.io/timer/, accessed on 14 May 2021).

\subsection{Expression Analysis of FABPs in CRC}

To reveal the gene expressions of $F A B P$ genes, we performed exploratory analyses using the Oncomine (https://www.oncomine.org accessed on 14 May 2021) [33] and GEPIA2 databases (http:/ / gepia2.cancer-pku.cn/\#index accessed on 14 May 2021) [34]. Oncomine is a platform consisting of 715 datasets containing 86,733 samples. This study used a set threshold for the interrogation of FABP gene expression profiles. To confirm differences in expressions across 20 different cancers, we used a significant $p$-value of $<0.05$, a multiple of change of 1.5 , and a gene rank in the top $10 \%$. We used the CCLE dataset (https: / / portals.broadinstitute.org/ccle accessed on 14 May 2021) to further examine the messenger (m)RNA expression levels of FABPs in cancer cell lines, and the expression data are displayed in heatmaps [35]. In this work, we also utilized GEPIA2 to look at the gene expression patterns of FABP genes in normal and CRC tissues. To evaluate paired tumor vs. normal samples, an analysis of variance (ANOVA) was performed, with the threshold absolute $\log$ base 2 of the fold change ( $\log _{2} \mathrm{FC}$ ) set to 1 and the value of $q$ set to 0.05 [36-43].

\subsection{Prognostics and Protein Expression Analysis of FABPs in CRC}

The distribution of FABP proteins in CRC tissues in the human body were investigated using the Human Protein Atlas (HPA) database (https: / / www.proteinatlas.org/ accessed 14 May 2021). More than 400,000 high-resolution pictures matched to more than 700 antibodies to human proteins are available in the HPA database [44,45]. Each intensity and fraction combination is automatically converted into a protein expression level score using the following formula: negative-not detected; weak - not detected; weak combined with either 25-75 percent or 75 percent-low; moderate-low; moderate combined with either 25-75 percent or 75 percent-medium; strong-medium, strong combined with either 25-75 percent or 75 percent-high. Furthermore, we also used the PrognoScan database to find correlations between $F A B P$ genes and patient prognoses in overall survival (OS). The PrognoScan database is a meta-analysis database that is used to show a gene's predictive value [46].

\subsection{Functional Enrichment Analysis of FABPs in CRC}

To study the list of classes of genes or proteins in terms of biological functions which may have a relationship with a disease phenotype, this research used an integrative analysis involving several databases such as STRING, cBioPortal, and MetaCore [47-52]. The STRING database (https: / / www.string-db.org/ accessed on 14 May 2021), consisting of 24,584,628 proteins from 5090 organisms, was used to reveal protein-protein interactions (PPIs) [53,54]. Meanwhile, to study interconnections between FABP genes, we used the cBioPortal database, results of which we then displayed in correlation plots [55,56]. Lastly, we used the MetaCore (https: / / portal.genego.com/ accessed on 14 May 2021) platform to more deeply reveal the signaling pathways and biological processes of $F A B P$ genes in CRC [57-63]. 


\subsection{TIMER Analysis of FABPs in CRC}

TIMER (http:/ / timer.cistrome.org/ accessed on 14 May 2021) is a comprehensive database that provides analysis of immune infiltrates in various types of cancer [64-66]. We utilized this database to uncover the involvement of $F A B P$ genes in immune infiltrates in CRC. Through scatterplots, we present the relationships between the estimated infiltrate values and gene expressions levels, and we evaluated the significance level of the correlations at $p<0.05$.

\section{Results}

\subsection{Expression Analysis of FABPs in CRC Using Oncomine and GEPIA2}

Oncomine analysis was performed to evaluate the $F A B P$ gene family to understand the expression profiles of the $F A B P$ gene family in different cancer types. As shown in Figure 1, there were 20 studies that examined high mRNA expression levels of FABP 6 in CRC tissues, to which we assigned a significance level of $p<0.05$, multiple of change of 1.5 , and a gene rank in the top $10 \%$. Next, the mRNA expression levels of $F A B P$ family members in CRC cell lines are also presented using CCLE analysis (Figure 1). The high mRNA expression of FABPs in some cell lines is indicated by the red color in the heatmap shown in Figure 2.

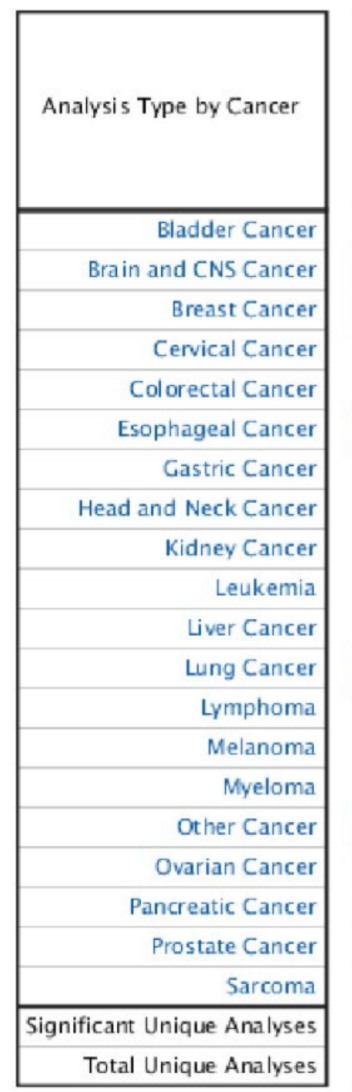

\section{FABP1 FABP2}

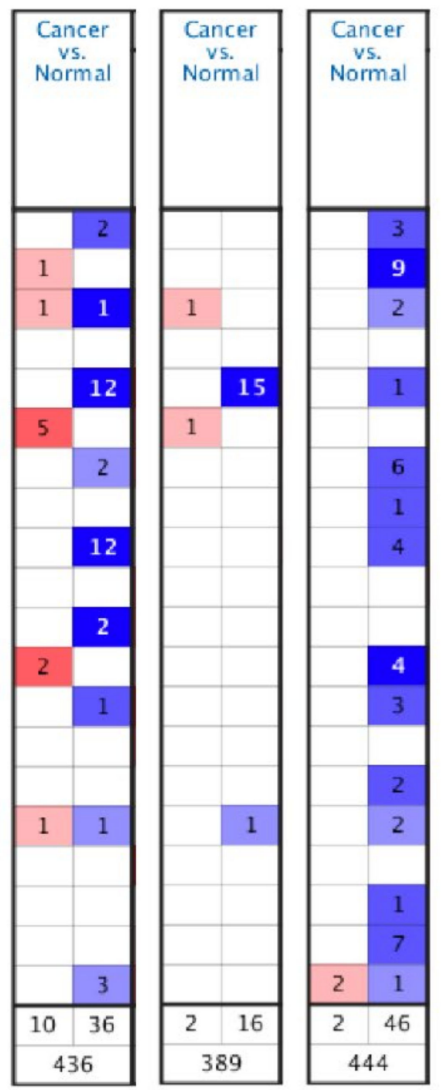

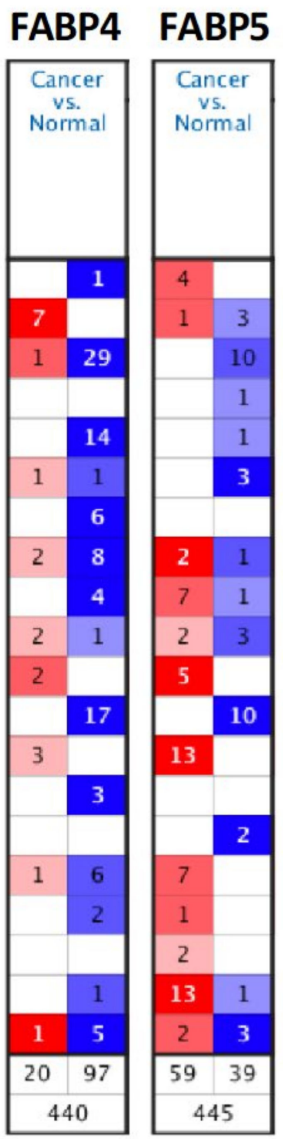
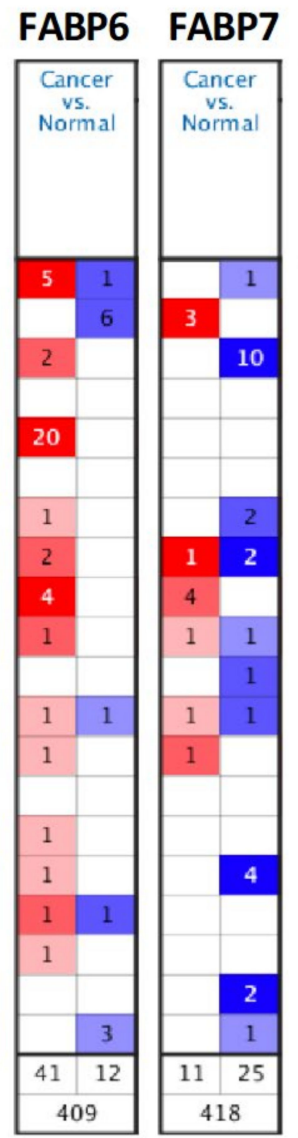

FABP9
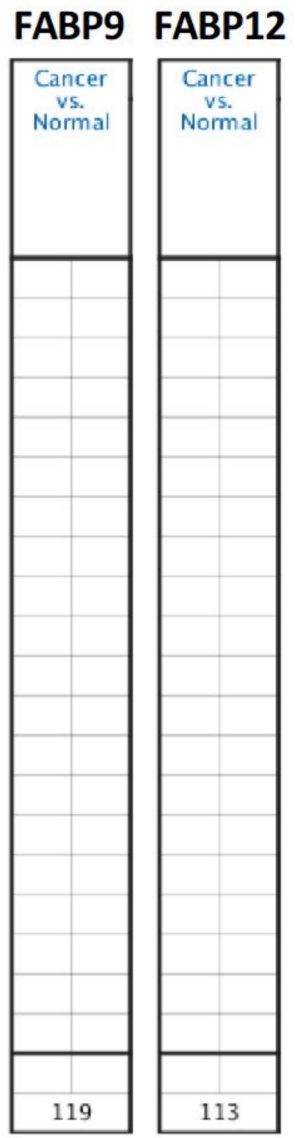

Figure 1. The mRNA expression study of fatty acid-binding proteins (FABPs) in normal and CRC tissues (Oncomine database). Color gradients represent gene ranking percentiles; a significant level was accepted at $p<0.05$, a multiple of change of 1.5 , and a gene ranking in the top $10 \%$. 


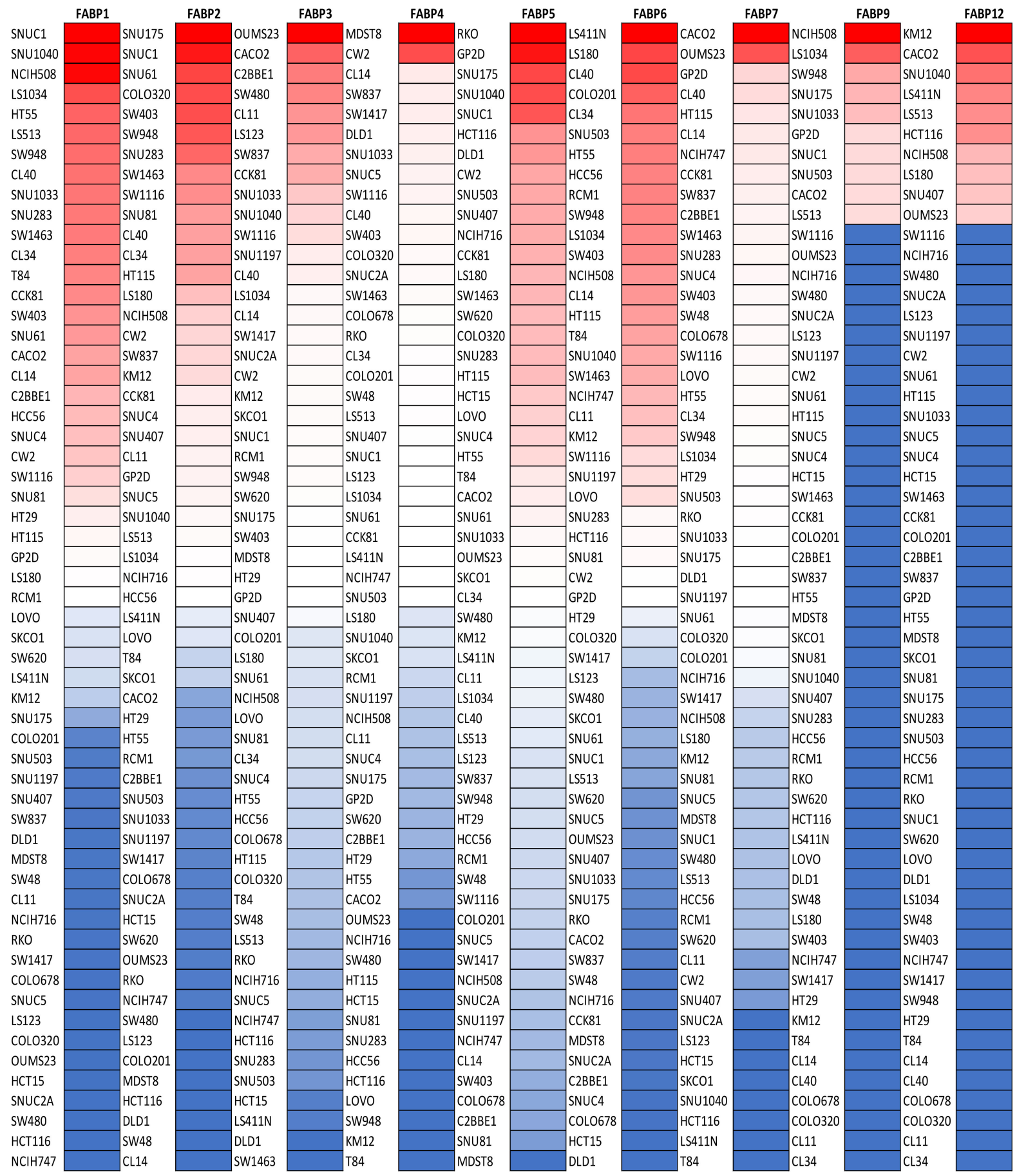

Figure 2. Heatmap of fatty acid-binding protein (FABP) gene mRNA expressions in colorectal cancer cell lines (CCLEs), with red signifying overexpression and blue suggesting underexpression.

Next, to further examine the expression levels of $F A B P$ family members in CRC, we performed a GEPIA2 analysis. According to the analytical results from GEPIA2 (Figures 3 and 4), the $F A B P 1$ and $F A B P 6$ genes had different and significant expressions in CRC (Figure 3A,B). Meanwhile, FABP2, FABP3, FABP4, FABP5, FABP7, FABP9, and FABP12 exhibited no significant differences in CRC (Figure 3). We also present in boxplot visualizations comparisons of the expressions of $F A B P$ genes in normal, colon adenocarcinoma (COAD), and rectal adenocarcinoma (READ) tissues (Figure 4), which showed that the $F A B P 1, F A B P 4$, and $F A B P 6$ genes had significantly different expression levels in normal and CRC tissues (Figure 4A). Furthermore, the association of expression levels of $F A B P$ 
family members with clinicopathological parameters in CRC patients was investigated. As shown in Figure 4B, we found that the mRNA expression levels of FABP3 or FABP4 were related to different tumor stages of CRC. However, mRNA expression levels of $F A B P 1$, $F A B P 2$, FABP5, FABP6, FABP7, FABP9, or $F A B P 12$ did not significantly differ in different tumor stages in CRC patients. This result is consistent with a previous study which also showed that FABP6 may play an important role in early carcinogenesis, but not in cancer stage progression in CRC [18].

(A)
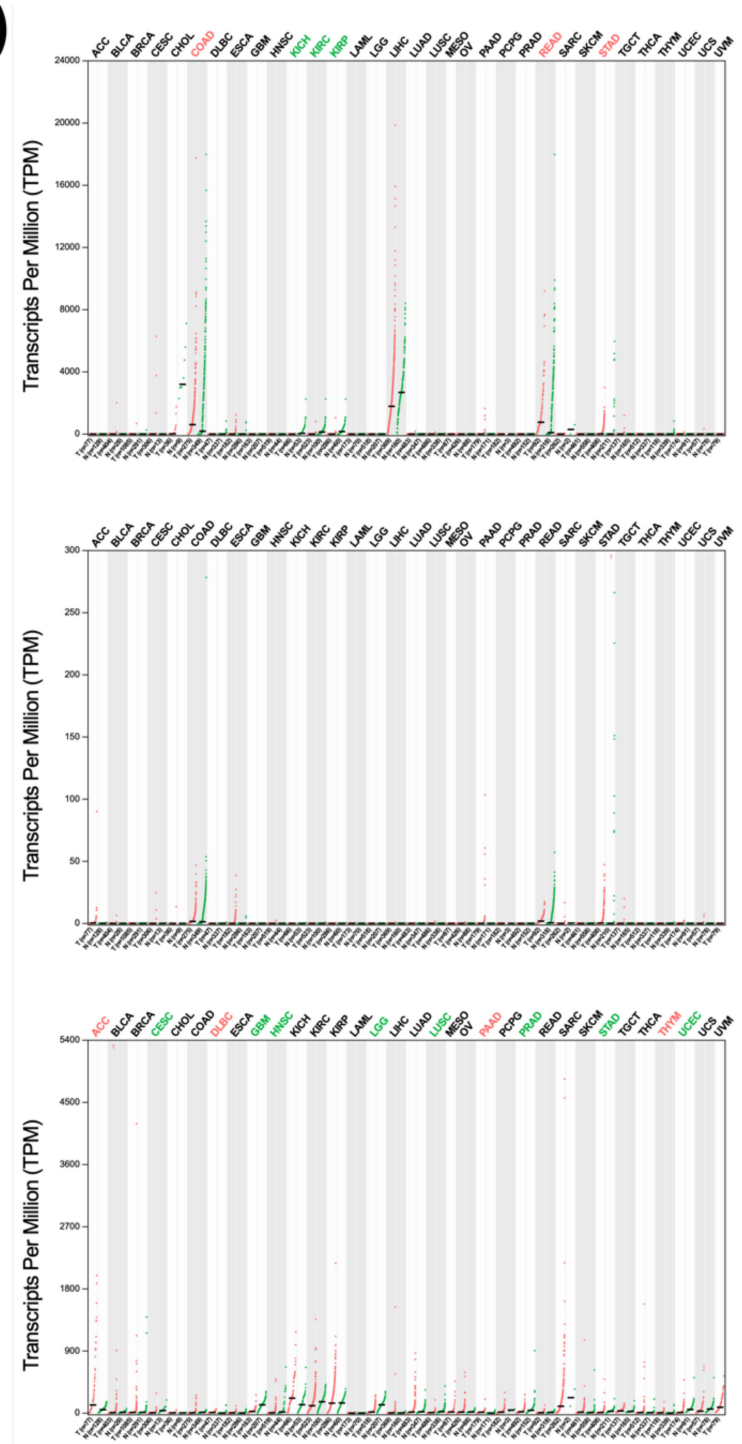

FABP1

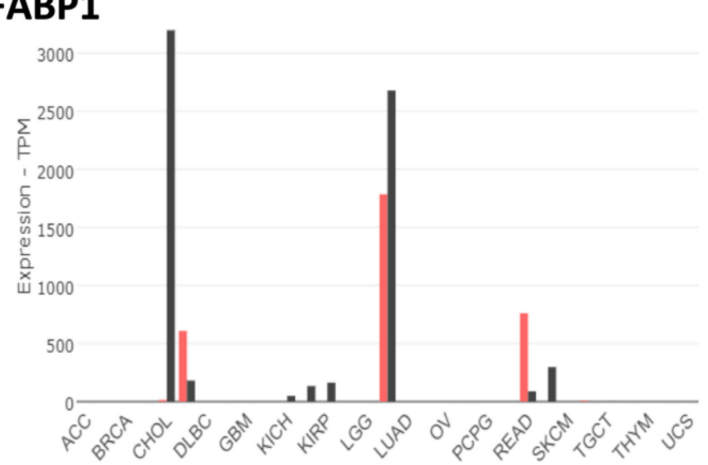

\section{FABP2}

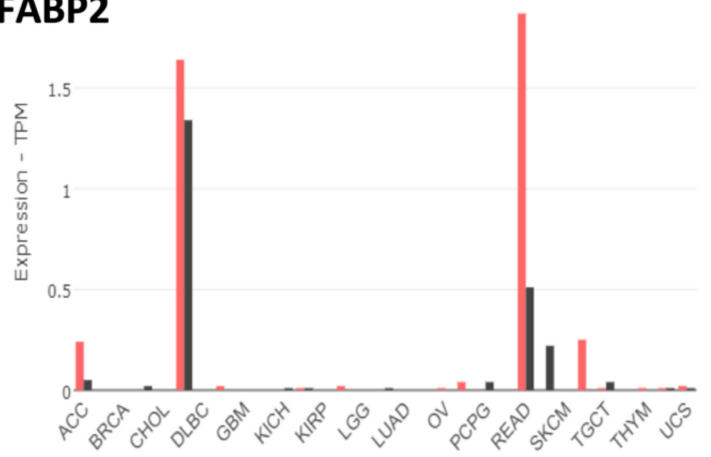

\section{FABP3}

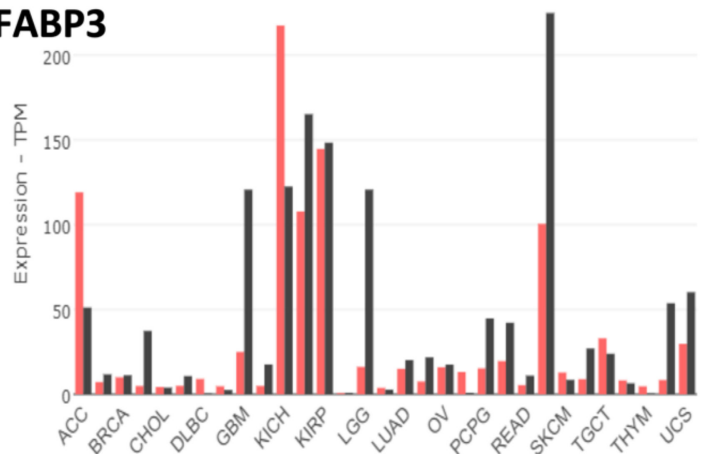

Figure 3. Cont. 
(B)

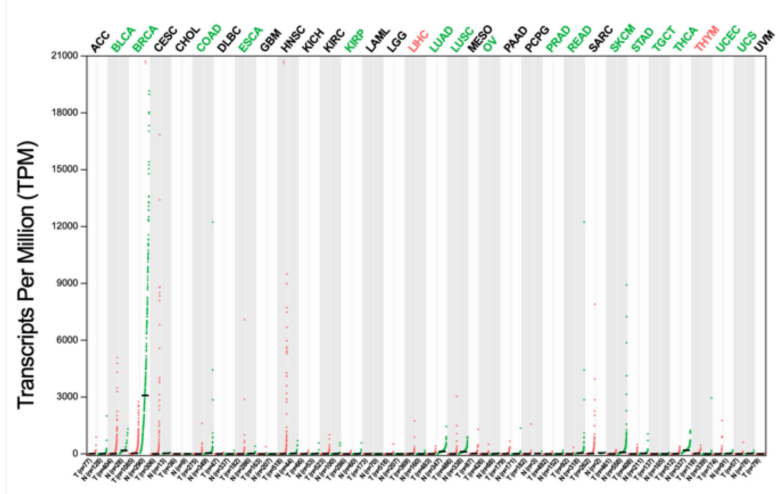

FABP4

FABP5
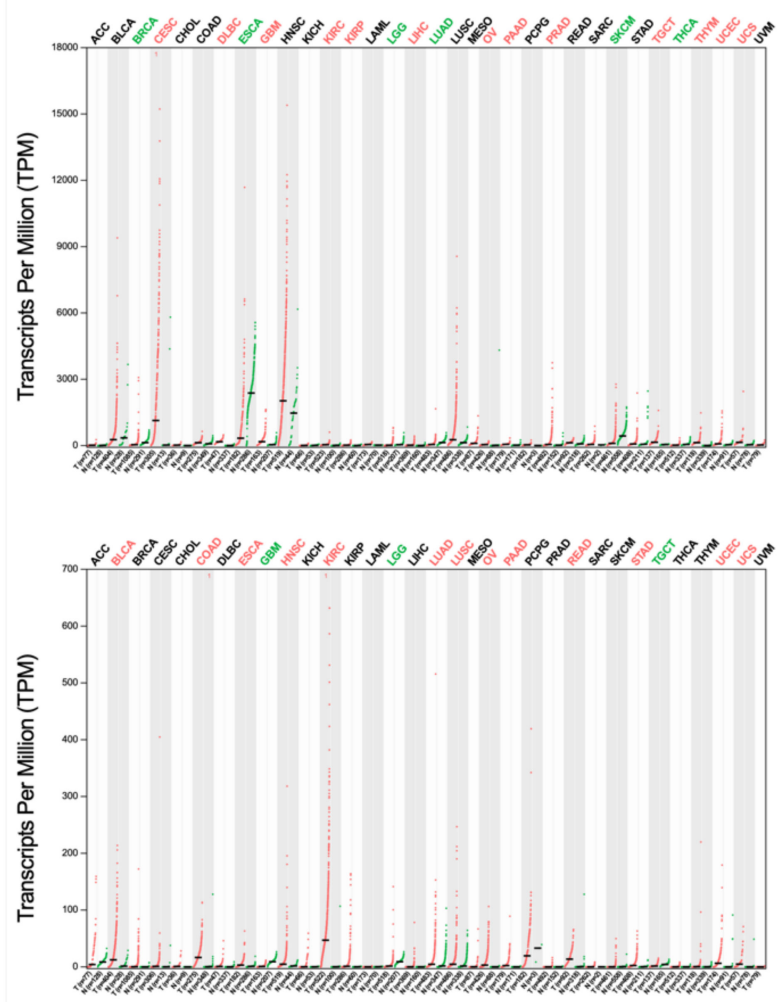
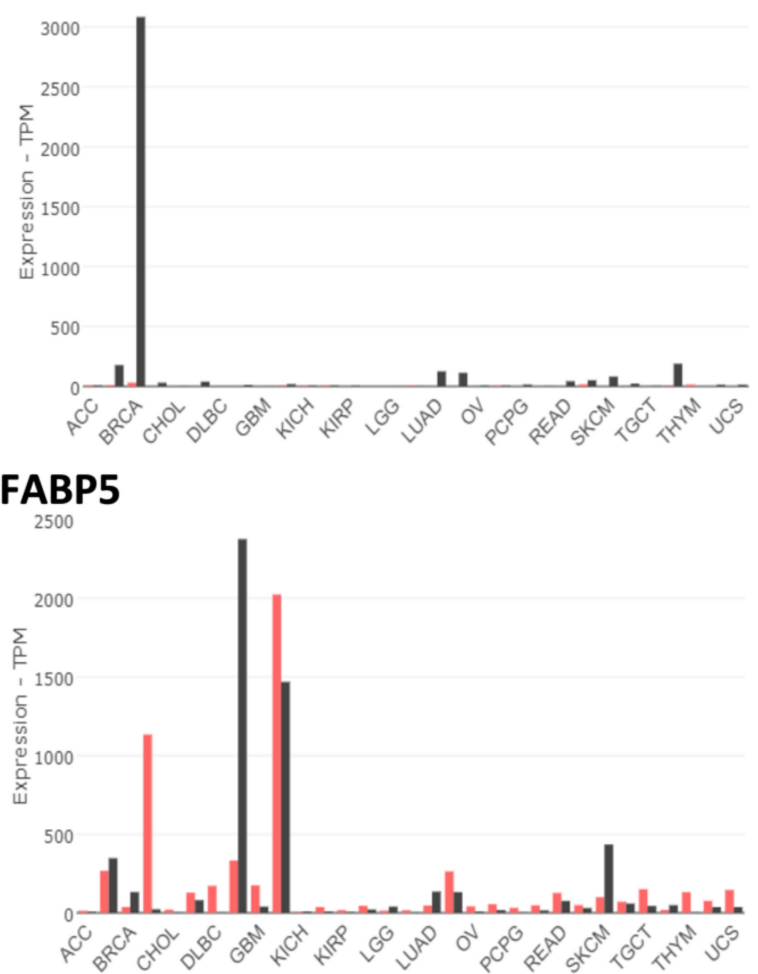

Tumor

- Normal

Iumor

- Normal

FABP6

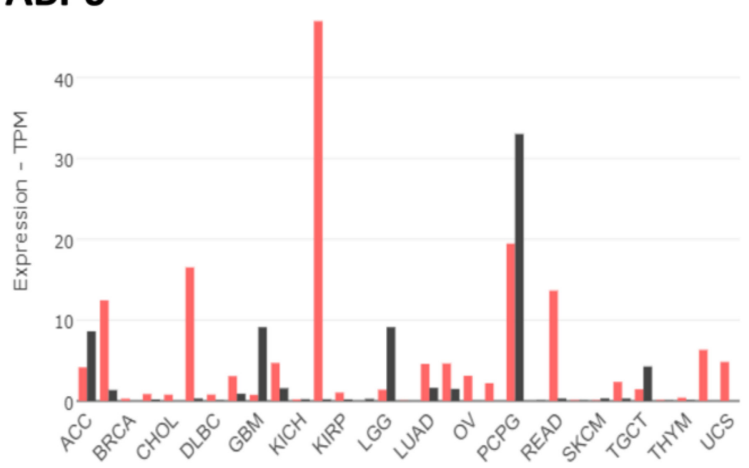

Figure 3. Cont. 
(C)

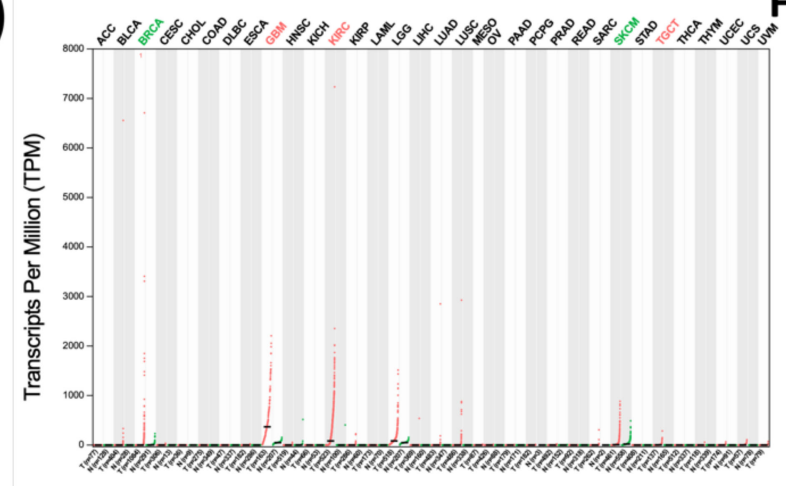

FABP7

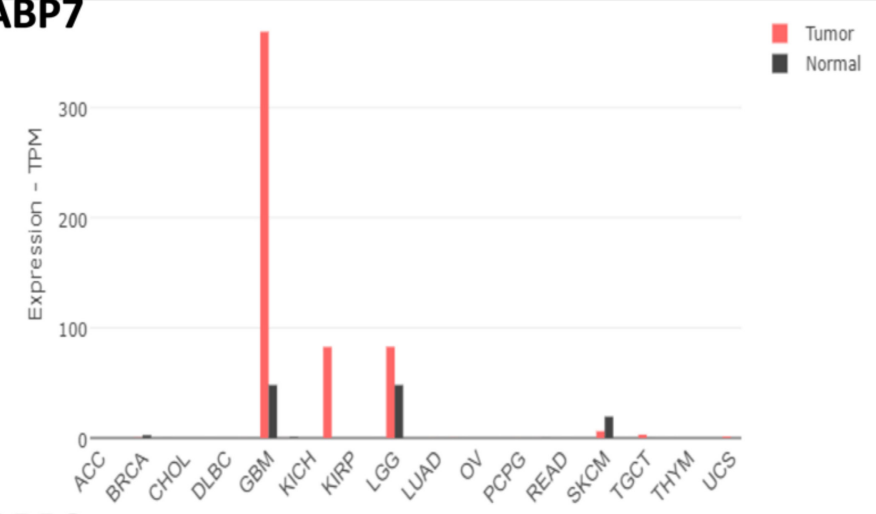

FABP9

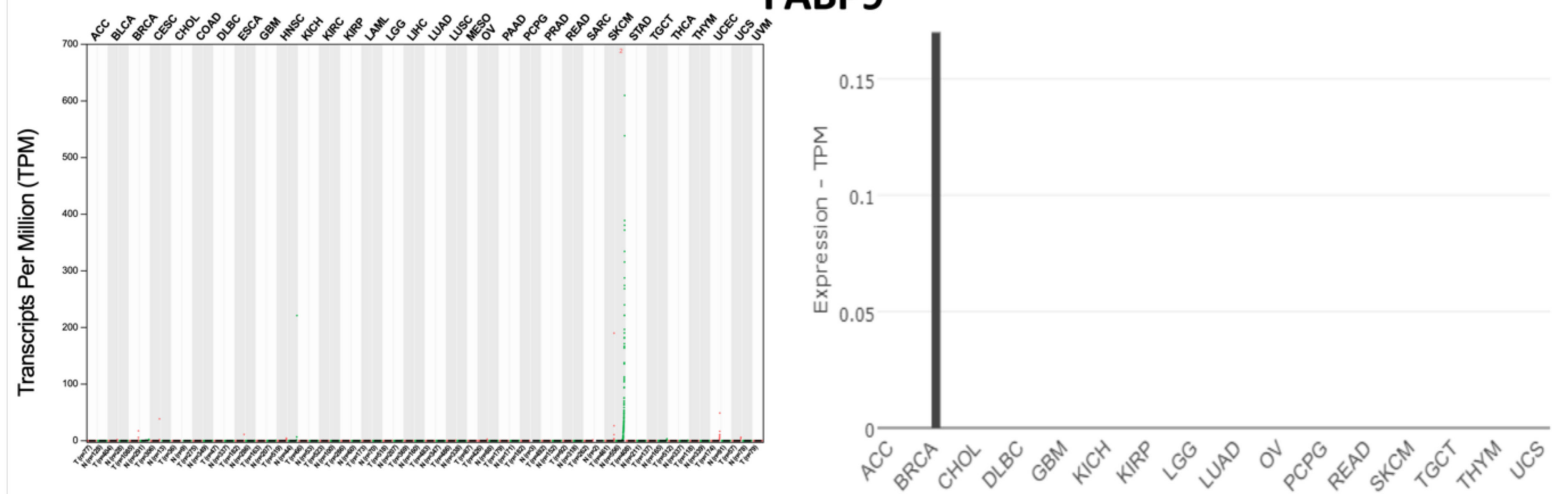

FABP12

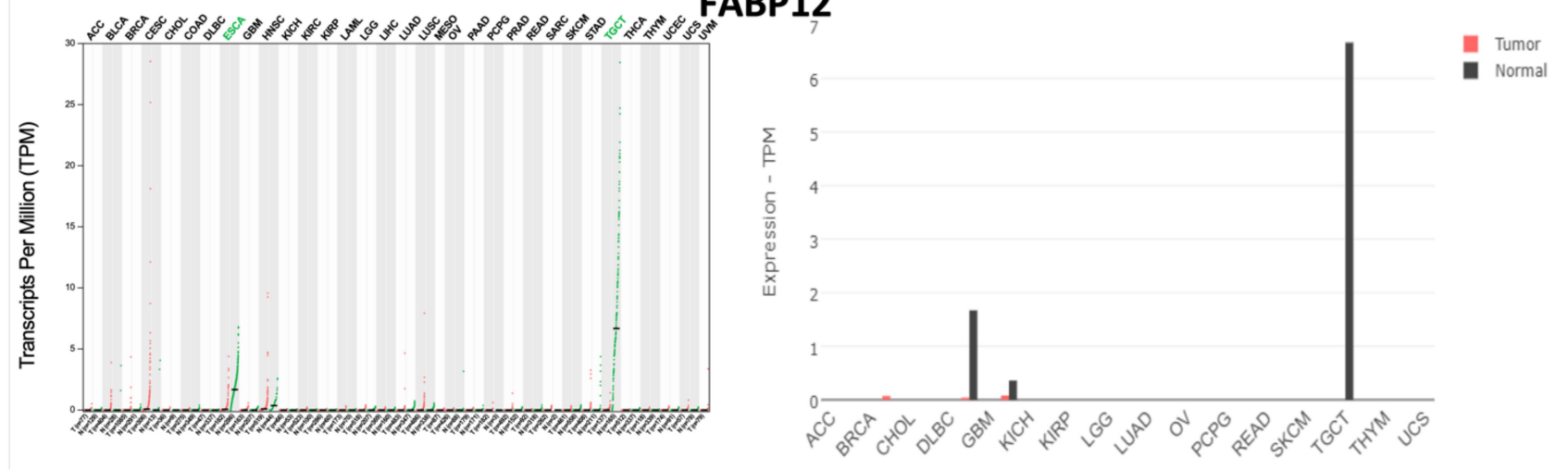

Figure 3. The gene expression profile of fatty acid-binding proteins (FABPs) (A) FABP1, FABP2 and FABP3; (B) FABP4, FABP5 and FABP6; (C) FABP7, FABP9 and FABP12 across 27 TCGA tumor samples and paired normal tissues using GEPIA (Gene Expression Profiling Interactive Analysis) webserver. The red bar indicates the expression of FABP genes in tumor tissues, while black indicates the expression in normal tissues. For each TCGA tumor (red), its matched normal and GTEx data (green) are given; T: tumor; N: normal; $n$ : number. $Y$ axis: transcript per million $(\log 2(\mathrm{TPM}+1))$. $\mathrm{X}$ axis: number of tumor and normal samples. ACC, adrenocortical carcinoma; BLCA, bladder urothelial carcinoma; BRCA, breast invasive carcinoma; CESC, cervical squamous cell carcinoma and endocervical adenocarcinoma; CHOL, cholangiocarcinoma; COAD, colon adenocarcinoma; DLBC, lymphoid neoplasm diffuse large B-cell lymphoma; ESCA, esophageal carcinoma; GBM, glioblastoma multiforme; HNSC, head and neck squamous cell carcinoma; KICH, kidney chromophobe; KIRC, kidney renal clear cell carcinoma; KIRP, kidney renal papillary cell carcinoma; LAML, acute myeloid leukemia; LGG, brain lower-grade glioma; LIHC, liver hepatocellular carcinoma; LUAD, lung adenocarcinoma; LUSC, lung squamous cell carcinoma; MESO, mesothelioma; OV, ovarian serous cystadenocarcinoma; PAAD, pancreatic adenocarcinoma; PCPG, pheochromocytoma and paraganglioma; PRAD, prostate adenocarcinoma; READ, rectum adenocarcinoma; SARC, sarcoma; SKCM, skin cutaneous melanoma; STAD, stomach adenocarcinoma; TGCT, testicular germ cell tumors; THCA, thyroid carcinoma; THYM, thymoma; UCEC, uterine corpus endometrial carcinoma; UCS, uterine carcinosarcoma. 
(A)
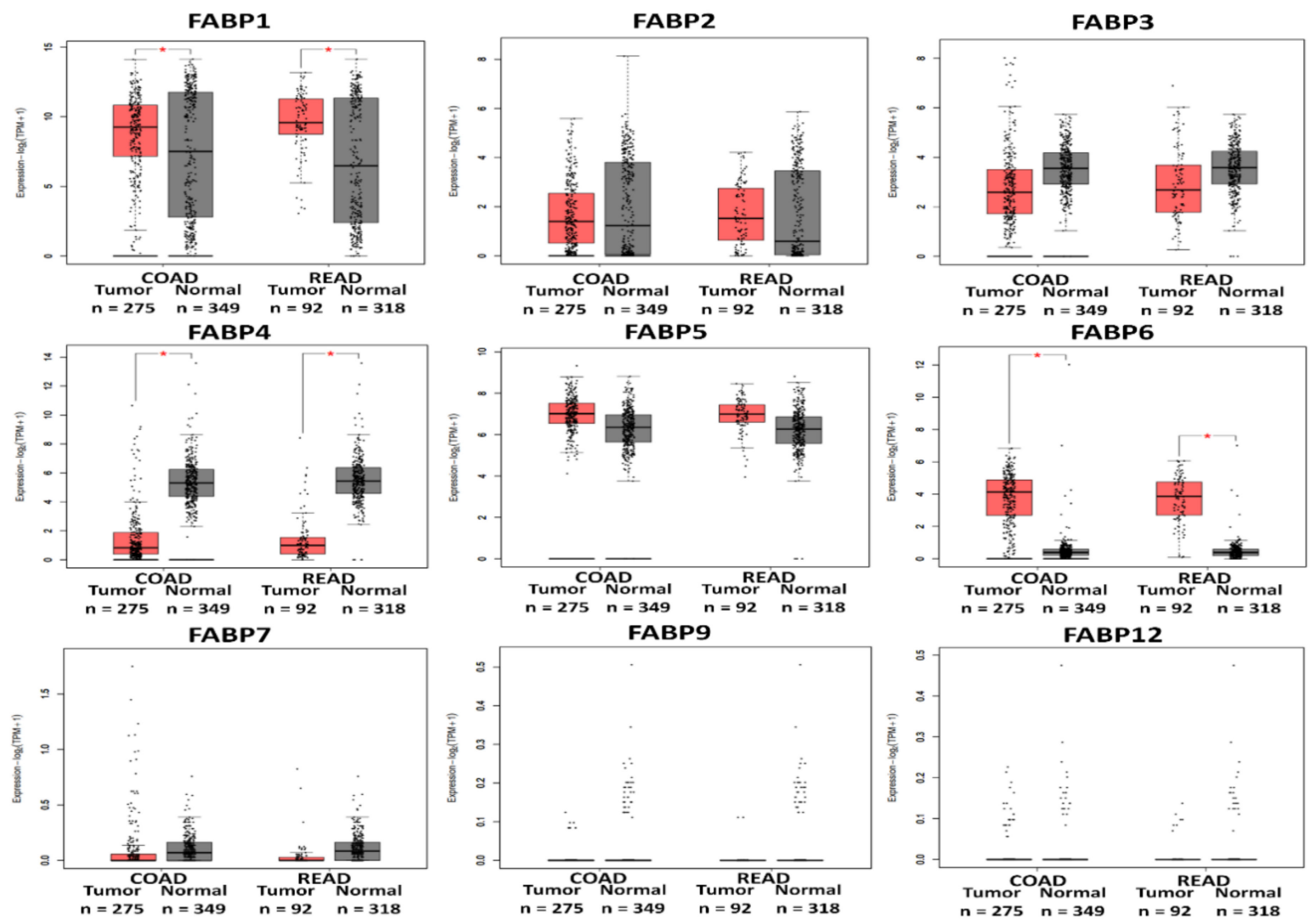

(B)
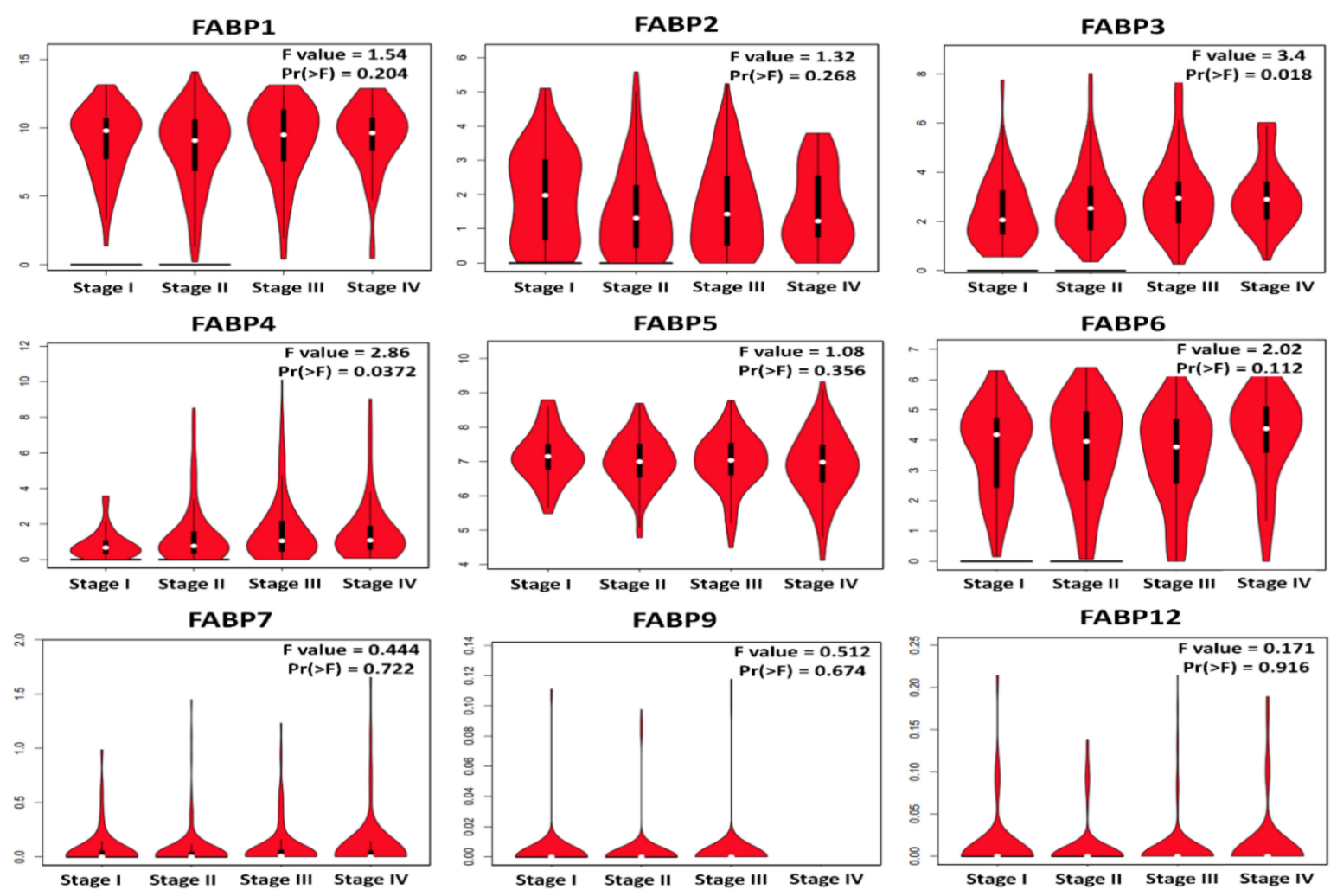

Figure 4. Gene expression profile of the fatty acid-binding proteins ( $F A B P \mathrm{~s})$ in CRC. (A) Gene expression analysis of $F A B P \mathrm{~s}$ genes using GEPIA based on TCGA database. Boxplot of transcriptional levels of FABPs in terms of $\log _{2}(\mathrm{TPM}+1)$ in COAD $(n=275)$ vs. normal samples $(n=349)$ and READ $(n=92)$ vs. normal samples $(n=318)$. Red indicates the FABP genes transcriptional levels in COAD and READ tissues, while black indicates the transcriptional levels in normal tissues. 
The method for differential analysis was one-way ANOVA. Statistical significance is indicated by $p<0.05$. (B) Gene expression analysis across the stages of the FABPs genes in colorectal cancer. The violin plot shows comparisons of the expressions of the FABP genes family from TCGA data in CRC during cancer progression. Violin plots represent $\log _{2}(\mathrm{TPM}+1)$ of genes in stage $1 \mathrm{CRC}$, stage $2 \mathrm{CRC}$, stage $3 \mathrm{CRC}$, and stage $4 \mathrm{CRC}$. An independent $t$-test was used to calculate $p$-values; $p<0.05$ was considered statistically significant; $\operatorname{Pr}(>F)<0.05$, based on Student's $t$-test. Values are the mean \pm SEM. TPM, transcript per million.

\subsection{Prognostic Value and Protein Expression Analysis of FABPs in CRC}

This paper presents an examination of CRC patient survival using a survival curve to assess the predictive relevance of $F A B P$ family member expression levels in predicting survival outcomes of CRC patients. Survival statistics of 55 CRC patients, as well as the hazard ratios (HR) and $p$-values for statistical significance are shown in Figure 5. Regarding overall survival (OS), we found that FABP4 (Cox $p=0.027956$, hazard ratio (HR) $(95 \%$ confidence interval $(\mathrm{CI}))=1.25(1.02-1.54))$ and FABP6 (Cox $p=0.009886, \mathrm{HR}(95 \%$ $C I)=1.51(1.10-2.07))$ were significantly correlated with the prognosis of CRC patients. FABP1 $($ Cox $p=0.387885, \mathrm{HR}(95 \% \mathrm{CI})=1.30(0.72-2.34))$, FABP2 (Cox $p=0.975840, \mathrm{HR}$ $(95 \% \mathrm{CI})=0.98(0.27-3.58))$, FABP3 $($ Cox $p=0.734289, \mathrm{HR}(95 \% \mathrm{CI})=1.13(0.56-2.27))$, FABP5 (Cox $p=0.444368, \mathrm{HR}(95 \% \mathrm{CI})=0.75(0.36-1.57))$, and FABP7 (Cox $p=0.165921$, $\mathrm{HR}(95 \% \mathrm{CI})=0.10(0.00-2.63))$ were not significantly correlated with the prognosis of CRC patients.

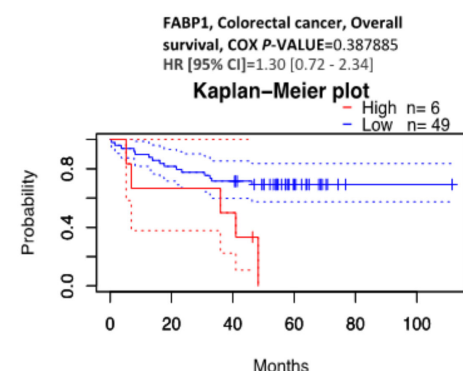

Months
FABP4, Colorectal cancer, Overall FABP4, Colorectal cancer, Overal
survival, cOX P-VALUE $=0.027956$ HR $[95 \% \mathrm{Cl}]=1.25[1.02-1.54]$
Kaplan-Meier plot

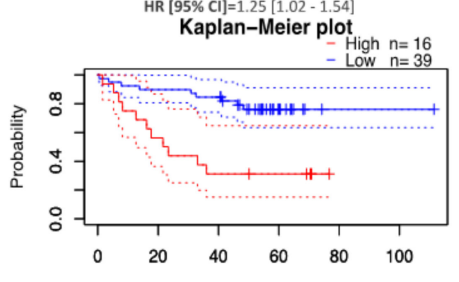

$$
\text { Months }
$$

FABP7, Colorectal cancer, Overall survival, COX P-VALUE $=0.16592$
HR $[95 \% \mathrm{CI}]=0.10[0.00-2.63]$

Kaplan-Meier plot

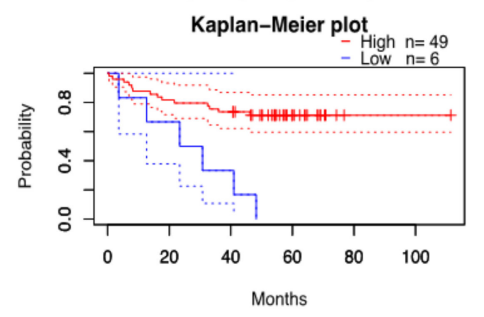

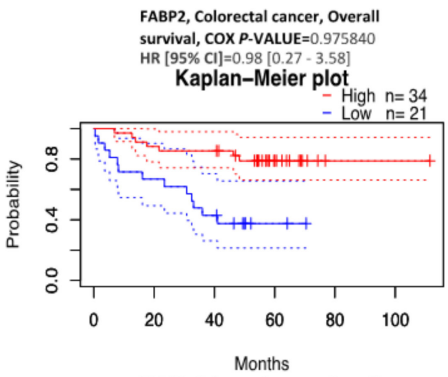

Months
FABP5, Colorectal cancer, Overall survival, COX P-VALUE $=0.444368$
HR $[95 \%$ CI] Kaplan-Meier plot
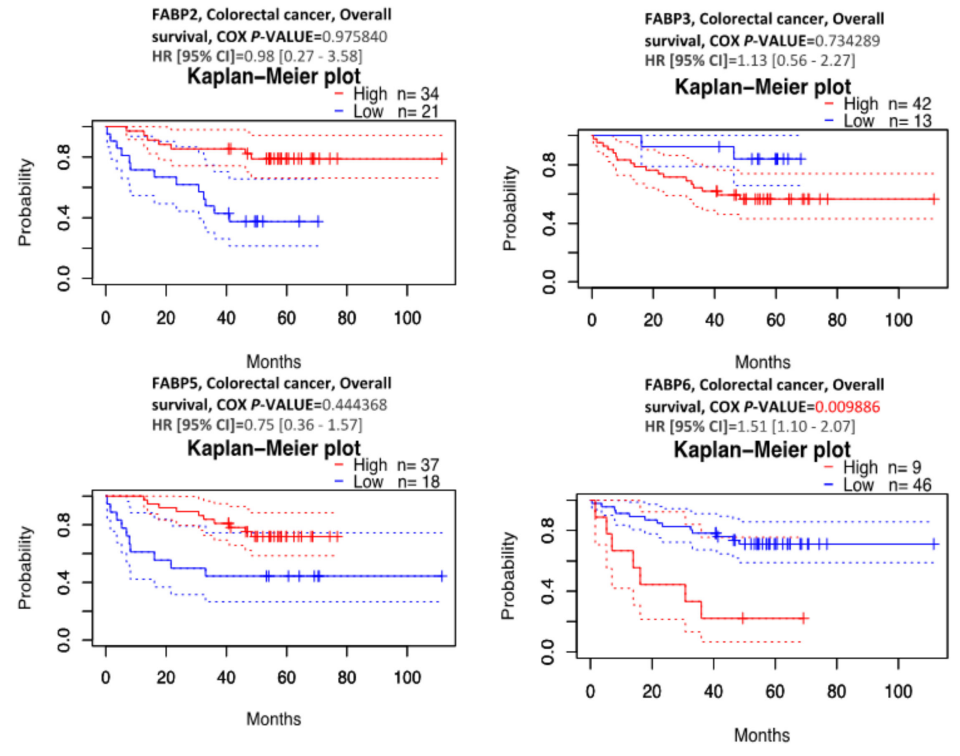

Figure 5. Kaplan-Meier plot of fatty acid-binding protein $(F A B P)$ expression in CRC patients $(n=55)$ for overall survival analysis (PrognoScan database). The survival curves for the high (red) and low (blue) expression groups are dichotomized at the optimum cutpoint. The time on the X-axis corresponds to the survival rate on the Y-axis. Dotted lines also show the 95 percent confidence intervals for each group. The hazard ratio (HR) is a relative prognostic measure of patients with CRC. $\log (\operatorname{rank} p)$ was used to determine the level of prognostic significance of patients with CRC. Furthermore, log (rank $p<0.05$ ) was interpreted as a significant difference in the prognostic expression of patients with CRC. The prognostic value of FABP4 and FABP6 showed significance in terms of overall survival outcomes in CRC (Cox $p<0.05)$. 
Next, we validated the protein expression levels of $F A B P$ family members in CRC tissues using the Human Protein Atlas (HPA) database. The representative IHC images of immunoreactivity expression in cancer specimens (Figure 6, Table S1) are shown. Manual scoring of immunohistochemistry data for staining intensity (negative, weak, moderate, or strong) and proportion of stained cells ( 25 percent, $25-75$ percent, or $>75$ percent) determined the protein expression score. The protein expression levels of $F A B P 1$ and $F A B P 6$ were higher in CRC tissues. Overall, FABP4 and FABP7 showed a moderate staining intensities, and we already knew that $F A B P 4$ has a role in the early development of CRC. However, since $F A B P 6$ showed strong intensity in IHC staining, we considered $F A B P 6$ to be a more-promising biomarker of CRC development. On the other hand, FABP2, FABP3, and $F A B P 5$ were underexpressed in CRC specimens.

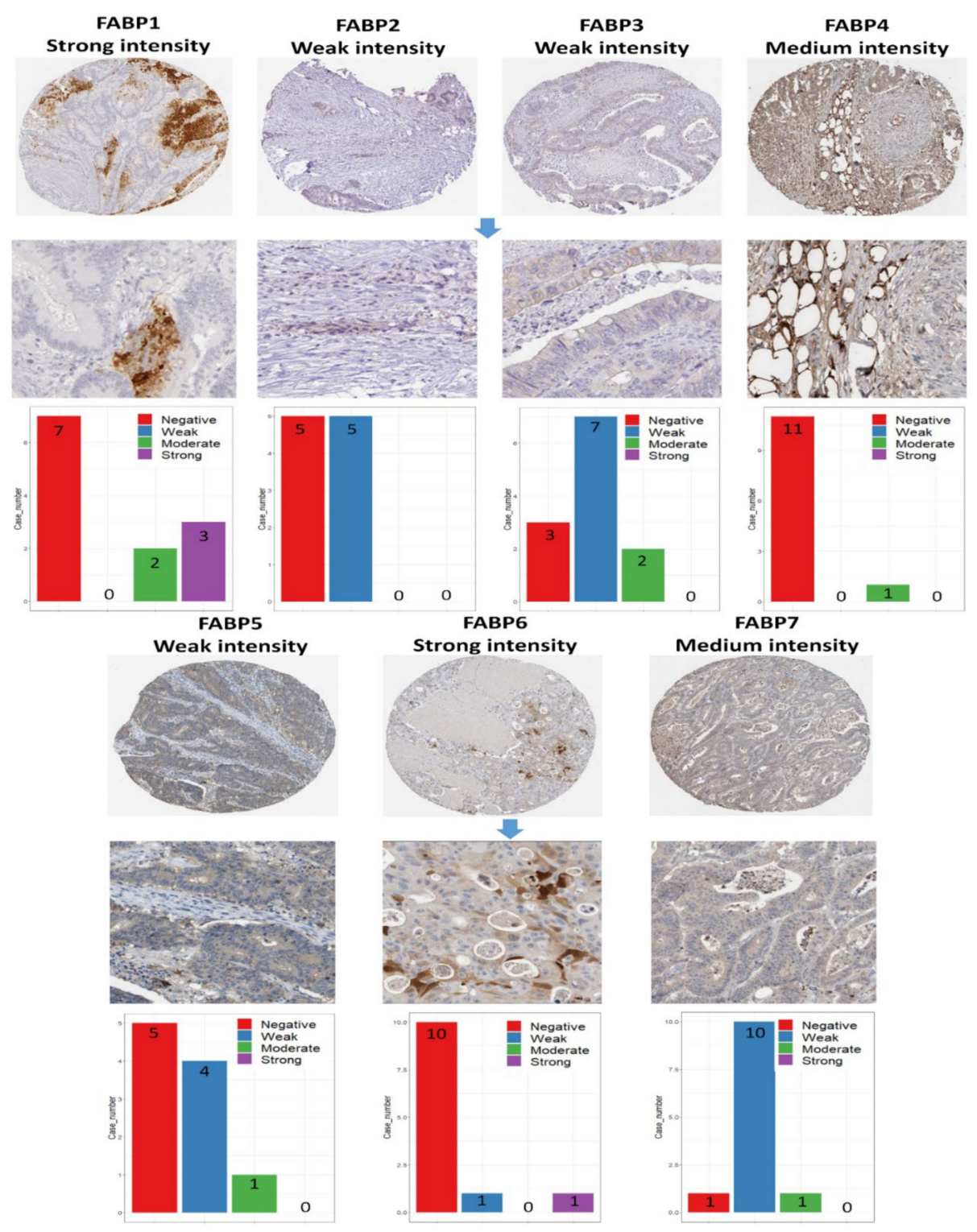

Figure 6. Analysis of protein expression using the HPA database in CRC tissue samples. The representative images of immunohistochemistry of $F A B P$ genes show their staining intensity, and the bar charts represent the quantification of IHC staining in CRC samples. Manual scoring of immunohistochemistry data for staining intensity (negative, weak, moderate, or strong) and proportion of stained cells (25 percent, 25-75 percent, or $>75$ percent) determined the protein expression score. FABP1 (11 patients), FABP2 (10 patients), FABP3 (12 patients), FABP4 (12 patients), FABP5 (10 patients), FABP6 (12 patients), and $F A B P 7$ (12 patients). FABP1 and FABP6 showed strong protein expressions in CRC, whereas FABP2, FABP3, FABP4, $F A B P 5$, and $F A B P 7$ showed low protein expressions in CRC. 


\subsection{Gene Correlation Analysis and Protein-Protein Interactions (PPIs) of FABPs in CRC}

To further explore the gene-gene interaction network and potential regulation of $F A B P$ s in CRC, we performed data mining and constructed an interaction network using cBioPortal and STRING online software. Based on the correlation analysis among $F A B P$ genes, we found that $F A B P 1$ was significantly and positively correlated with $F A B P 6$ using the cBioPortal database analysis (Figure 7A). According to above-mentioned results, the HPA database pointed out that not only did FABP6 protein expression show a strong intensity of staining, but also the FABP1 protein was highly expressed in CRC tissues, suggesting their potential correlation. In addition, $F A B P 1$ was also positively correlated with $F A B P 3$, and $F A B P 3$ was positively correlated with $F A B P 5$. Thus, a PPI network analysis was performed for FABP transport proteins using a STRING analysis. The PPI network yielded a number of edges and nine nodes. The impacts of the nine FABP transport proteins were largely related to fatty acid (FA) receptor binding and activity; in addition, FABP1 was demonstrated to increase free fatty acids (FFAs) absorption into the cytoplasm and facilitate transport to the nucleus, with a preference for longer-chain FAs [67]. The STRING database was also utilized to look at the top ten most often interacting adjacent proteins among the nine FABP family members. PPARG, ADIPOQ, PPARA, SLC10A2, LIPE, LPL, S100A7, APOA1, PLIN1, and NR1H4 were shown to be highly associated with FABP transport protein modulation and capacity in CRC patients (Figure 7B). SLC10A2 is a sodium/bile-acid cotransporter found in the ileum that is involved in the sodiumdependent reabsorption of bile acids from the small intestine lumen, as well as cholesterol metabolism [68]. Nuclear receptor subfamily 1 group H member 4 (NR1H4), also known as farnesoid $\mathrm{X}$ receptor (FXR), is a bile-acid receptor that promotes transcriptional activation of FABP6 as one of its target genes [69,70]. It was found that expression of NR1H4 is frequently downregulated by DNA methylation and Kirsten rat sarcoma (KRAS) signaling in colon cancer, which implies a negative relationship between NR1H4 and tumor growth [71].

(A)

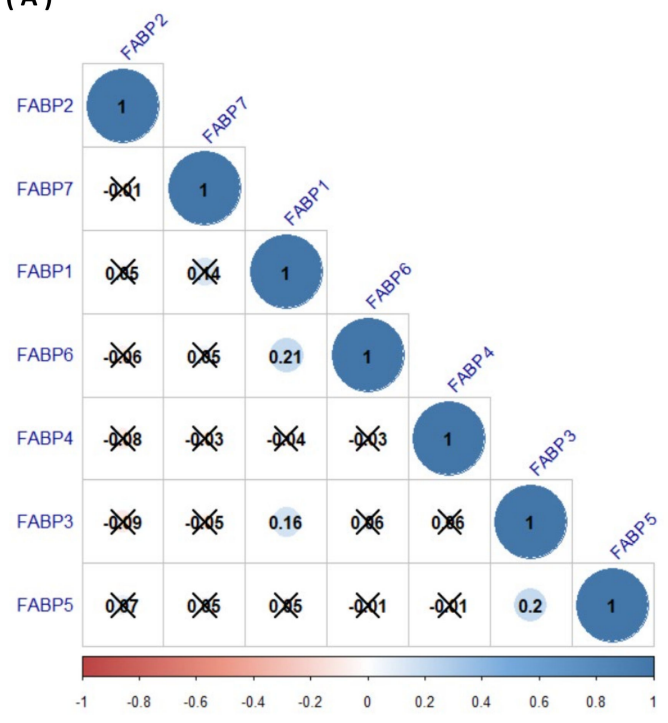

( B )

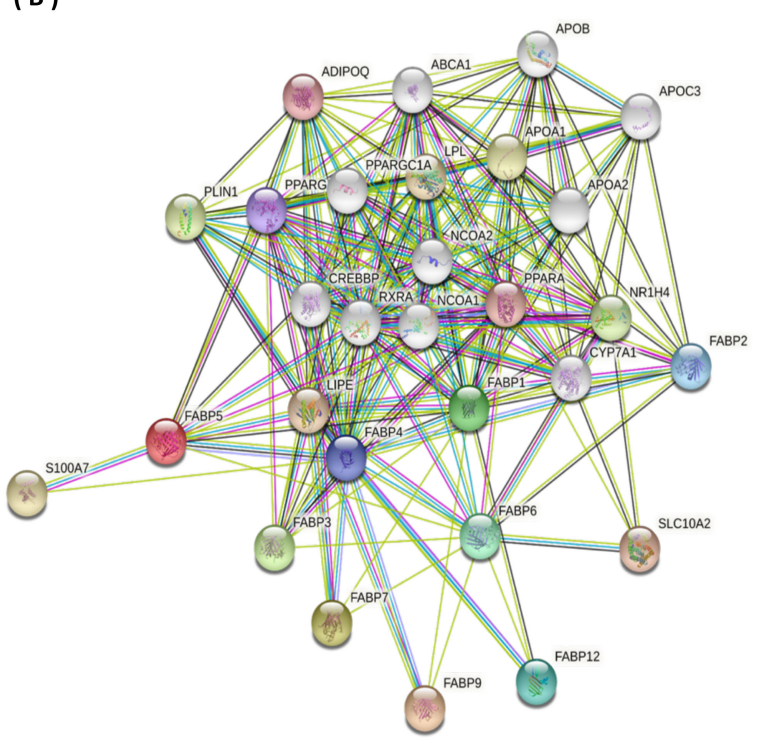

Figure 7. (A) Correlation analysis of fatty acid-binding protein ( $F A B P)$ genes in CRC (cBioportal database). Correlation plots among $F A B P$ family genes in CRC. Insignificant correlation values are indicated by crosses; $p<0.05$ was considered statistically significant. (B) Protein-protein interactions (PPIs) of FABPs family members (STRING database). Highly interacting proteins are represented as hub protein nodes in the PPI network. The nodes also show the known or anticipated three-dimensional protein structures. Proteins involved in cell death control are represented by red nodes. Proteins involved in the immune system are represented by green nodes. Proteins involved in neutrophil degranulation are represented by blue nodes. Proteins involved in RNA metabolism are represented by pink nodes. Proteins linked to chromatin DNA binding are represented by yellow nodes. The types of evidence supporting these hypothesized connections are shown by lines of different colors. 


\subsection{Functional Enrichment Analysis of FABPs Using the MetaCore Platform}

MetaCore has different biomolecular interactions revealing relevant signal pathways such as protein-protein, protein-DNA, and protein-metabolite connections. To reveal deeper biological processes, we leveraged the MetaCore platform by uploading co-expressed FABP gene data from The Cancer Genome Atlas (TCGA)-CRC dataset. The top $10 \%$ differentially expressed genes (DEGs) were submitted to MetaCore for paired CRC cancer samples and matched normal tissues. Analysis of biological processes revealed that the FABP1 gene had significant involvement in "recurrent gene fusions in prostate cancer", "transcription_FXR-regulated cholesterol and bile-acid cellular transport", and "transcription_HIF-1 targets" in CRC development (Figure S2, Table S2). This result confirms that $F A B P 1$ is positively correlated with FABP6, as we previously mentioned in the results of the gene correlation analysis. FABP1 has a role in bile-acid cellular transport regulated by FXR or NR1H4. Results of the transcriptome analysis revealed that the weaning transition changed the expression of genes involved in food transport and metabolism in the intestine. Weaning reduced the production of FABP1 in the gut, which is important for fatty acid (FA) metabolism. Weaning enhanced the expression of genes involved in bile-acid metabolism, such as FABP6 and FXR or NR1H4 [72]. FABP2 was significantly correlated with "estradiol metabolism", "retinol metabolism", and "PXR-mediated direct regulation of xenobiotic metabolizing enzymes/rodent version" in the development of CRC (Figure S3, Table S3). FABP3 was significantly correlated with "CHDI_correlations from replication data_causal network (positive correlations)", "rheumatoid arthritis (general schema)", and "immune response_immunological synapse formation" in the development of CRC (Figure S4, Table S4). FABP4 was significantly correlated with "immune response_lectininduced complement pathway", "immune response_classical complement pathway", and "COVID-19-associated coagulopathy" in the development of CRC (Figure S5, Table S5). FABP5 was significantly correlated with "DNA damage_intra S-phase checkpoint", "cell cycle_role of APC in cell-cycle regulation", and "DNA damage_role of Brca1 and Brca2 in DNA repair" in CRC development (Figure S6, Table S6). FABP6 was significantly correlated with "ubiquinone metabolism", "L-lysine metabolism", and "role of microRNAs in cell proliferation in colorectal cancer" in the development of CRC (Figure 8, Table S7). Discrepancies in the expressions of some genes were confirmed to be the cause of several human malignancies. In addition, several CRC patients with tumors of a histologically identical type had uneven responses to treatment and idiosyncratic symptoms. Micro (mi)RNAs have critical roles in a variety of biological functions, including cancer cell proliferation, invasion, and metastasis $[73,74]$. Some previous studies on miRNAs and hub genes involved in CRC identified 10 hub genes, SLC26A3, CLCA1, CLCA4, GUCA2A, GUCA2B, MS4A12, $K R T 20, A Q P 8, M A O A$, and $A D H 1 A$, four differentially expressed miRNAs, miR-423-5p, miR-552, miR-502-3p, and miR-490-5p [75], and a specific miRNA and its role in CRC by targeting specific hub genes [76-79]. FABP7 was significantly correlated with "breakdown of $\mathrm{CD}^{+}$T-cell peripheral tolerance in type 1 diabetes mellitus", "immune response_IL-12 signaling pathway", and "immune response_T-cell co-signaling receptors, schema" in CRC development (Figure S7, Table S8). FABP9 was significantly correlated with "putative role of Tregs in COPD", "breakdown of CD4 ${ }^{+}$T-cell peripheral tolerance in type 1 diabetes mellitus", and "immune response_IL-16 signaling pathway" in the development of CRC (Figure S8, Table S9). FABP12 was significantly correlated with "protein folding and maturation_posttranslational processing of neuroendocrine peptides", "translation_regulation of EIF2 activity", and "development_TGF-beta-dependent induction of EMT via MAPK" in CRC development (Figure S9, Table S10). 


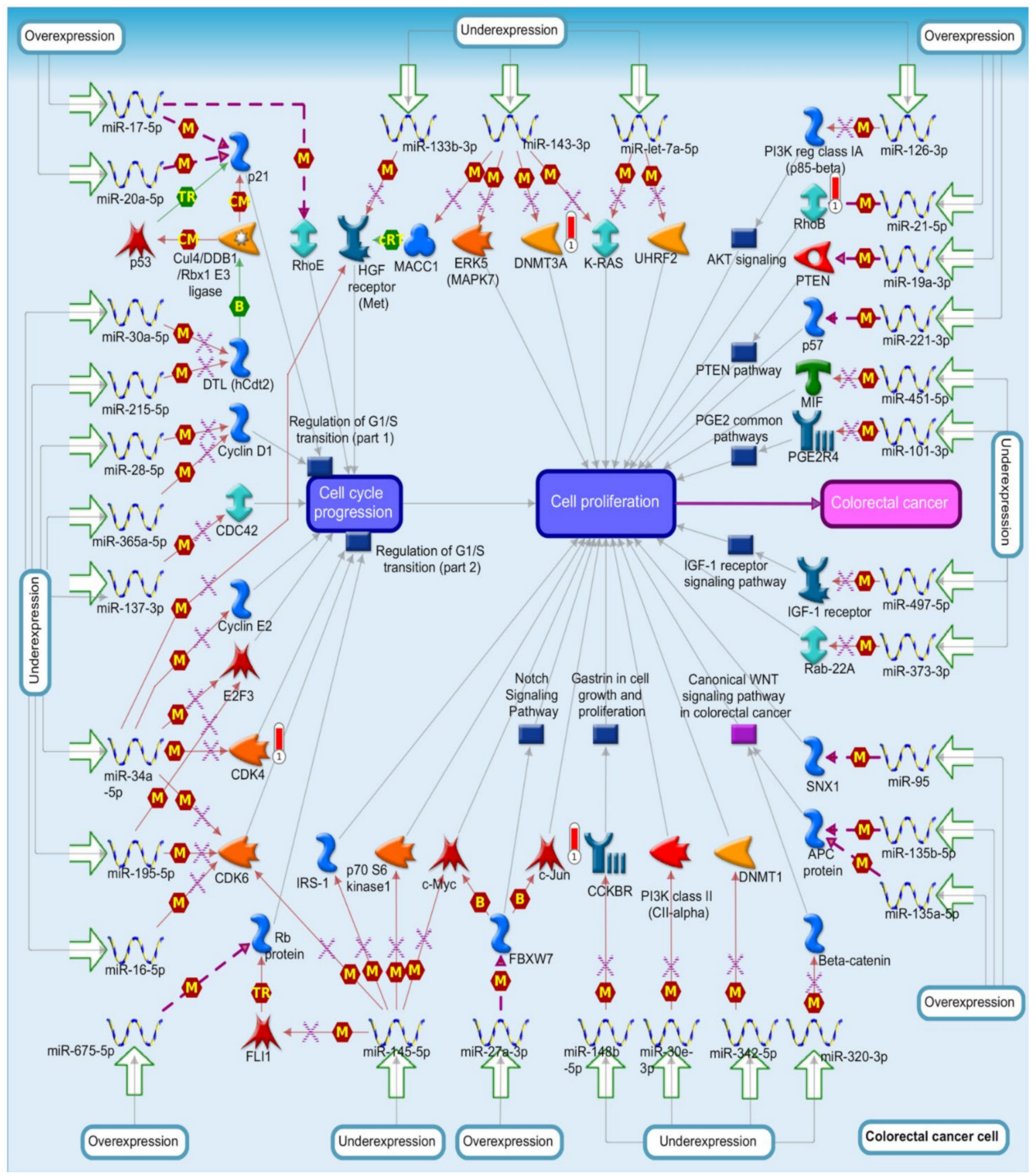

Figure 8. MetaCore pathway analysis of fatty-acid binding protein 6 (FABP6) co-expressed differentially expressed genes (DEGs) in colorectal cancer patient databases. FABP6 co-expressed genes in colorectal cancer from TCGA databases were acquired and identified by Venn diagram analysis. These 243 genes were further exported to the MetaCore pathway analysis tool to identify gene networks and signaling pathways. The "role of microRNAs in cell proliferation in CRC" was identified as one of the top three enriched pathways in the formation of CRC. The network suggested that the differential expression of microRNAs will lead to colorectal cancer cell progression. B, binding; CM, covalent modification; $+p$, phosphorylation; T, transformation; Tn, transport; Z, catalysis; TR, transcription regulation; IE, influence on expression; GR, group relation; CS, complex subunit. A green arrow represents (positive) activation of the process. A red arrow represents (negative) inhibition of the process. A gray arrow represents an unspecified process.

\subsection{Associations of FABP Gene Family Members with Immune Cell Infiltration}

In CRC patients, clinical outcomes are linked to the inflammatory response and immune cell infiltration, both of which are influenced by FABP family genes [80]. The TIMER database was used to comprehensively search to see whether FABP gene expressions were linked to immune infiltration in CRC patients (Figure 9 and Figure S1A-F). Analytical results showed a correlation between FABP6 and cluster of differentiation $4^{+}\left(\mathrm{CD}^{+}\right) \mathrm{T}$ cell, while macrophages and neutrophils were negatively correlated in COAD and READ patients (Figure 9). FABP1 was negatively correlated with $\mathrm{CD} 4^{+} \mathrm{T}$ cells and neutrophils in COAD and READ patients (Figure S1A). FABP2 was negatively correlated with $\mathrm{B}$ cells in COAD and READ patients (Figure S1B). FABP3 enhanced the infiltration of $\mathrm{B}$ cells and macrophages in READ patients and $\mathrm{CD}^{+}$in COAD patients (Figure S1C). There was a 
correlation between $F A B P 4$ and $\mathrm{CD} 4^{+} \mathrm{T}$ cells, while macrophages and neutrophils were definitely corelated in COAD and READ patients (Figure S1D). FABP5 was negatively correlated with B cells, macrophages, and dendritic cells in COAD patients (Figure S1E). In COAD and READ patients, there was no obvious linear correlation between FABP7 and immune cell infiltration (Figure S1F).

(A)
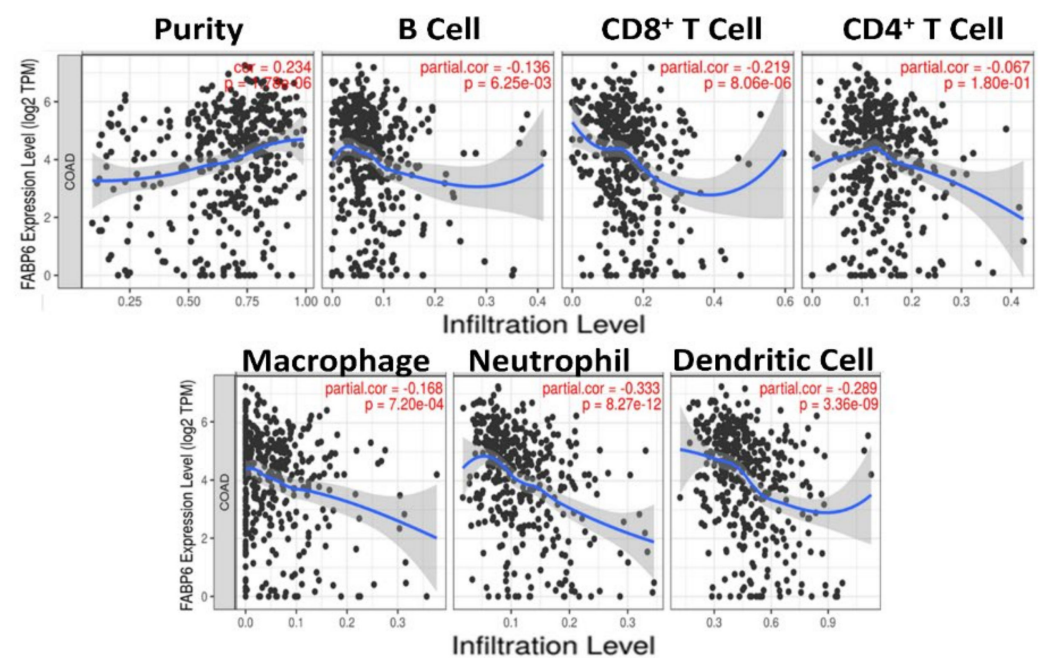

(B)
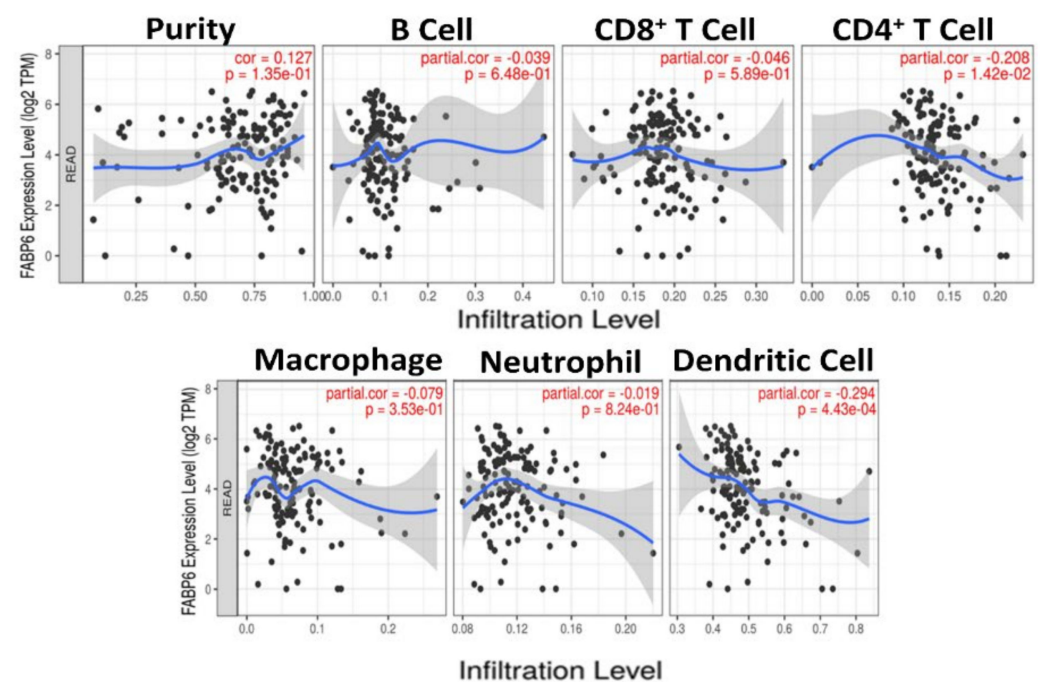

Figure 9. Correlations between differentially expressed fatty acid-binding protein 6 (FABP6) gene and immune cell infiltration in primary (A) colon adenocarcinoma (COAD) and (B) rectal adenocarcinoma (READ) patients. Analysis of the correlation between FABP6 gene overexpression and some tumor infiltration parameters in both COAD and READ patients was accomplished using TIMER. The figure shows that the FABP6 gene expression was associated with tumor purity and several tumorinfiltrating immune cell markers, such as $\mathrm{CD} 8^{+} \mathrm{T}$ cells, $\mathrm{B}$ cells, $\mathrm{CD} 4^{+} \mathrm{T}$ cells, neutrophils, macrophages, and dendritic cells. Spearman correlations were applied to describe correlations between $F A B P$ family genes and the abovementioned immune cells ( $p<0.05$ was accepted as statistically significant).

\section{Discussion}

FABPs are a group of FA transport proteins. FABPs are tiny $(12-15 \mathrm{kDa})$ cytosolic proteins that are abundant in organs with active lipid metabolism, such as the heart and liver, as well as cell types specialized in lipid storage, trafficking, and signaling, such as adipocytes and macrophages. [81]. We explored mRNA expression levels, correlations with clinicopathologic parameters, and prognostic values of nine $F A B P$ genes in patients with CRC. The majority of these genes had altered expressions that could impact the survival of patients with cancer. FABP6 might be a viable therapeutic target for colorectal 
cancer. FABP6 expression was enhanced in CRC tissues compared to normal tissues, which is consistent with a recent study that found increased expression of this $F A B P$ in CRC [18]. We discovered that elevated FABP4 and FABP6 expressions were linked to a poor prognosis in CRC patients. In addition, we found that $F A B P 6$ was significantly correlated with the "role of microRNAs in cell proliferation in colorectal cancer" in the development of CRC using MetaCore analysis. In the present study, our main focus was on FABP6 because its expression is significantly overexpressed in CRC. In our previous study of prostate cancer, we discovered that miR-320 inhibited the canonical Wnt/ $\beta$-catenin pathway, which means this miRNA plays a role in malignant transformation and cancer initiation [82]. Activation of the Wnt/ $\beta$-catenin pathway plays an important role in human CRC tumorigenesis [83]. Moreover, our very recent study identified that FABP6 is the Wnt signaling pathway molecule which may indirectly interact with $\beta$-catenin [84]. Therefore, the correlations among $F A B P 6$, miR-320, and the $W n t / \beta$-catenin pathway in CRC need to be further explored.

The tumor microenvironment plays an important role in tumor progression. Tumorassociated macrophages (TAMs) were reported to promote proliferation, invasion, metastasis, angiogenesis, and immunosuppression. High TAMs levels were significantly related to worse progression-free survival and a poorer response rate than low TAMs levels $[85,86]$. In addition to macrophages, another biomarker correlated with the cancer-associated systemic inflammatory response is increased circulating neutrophil counts. Neutrophils produce cytokines and chemokines, which are crucial in the development of cancer. Lymphocytes, on the other hand, can aid in the development of a cytotoxic immune response to cancer. Previous research has found that a reduction in serum lymphocyte counts has a detrimental impact on CRC patients' prognoses [87-89]. The neutrophil-lymphocyte ratio (NLR) was found to be a significant surrogate measure for OS and cancer-specific survival (CSC) in a study of 12,118 patients, including 1413 CRC patients [90]. Numerous studies have shown that the NLR can be utilized as a major predictor of CRC patient survival, despite the fact that the characteristics of the patients recruited and the ideal NLR cutoff levels differed from study to study [91]. Another lymphocyte that helps coordinate the immune response to fight infection is $\mathrm{CD} 4^{+} \mathrm{T}$ lymphocytes, by stimulating other immune cells, such as macrophages, $\mathrm{B}$ lymphocytes (B cells), and CD8 ${ }^{+} \mathrm{T}$ lymphocytes (CD8 cells). CD4 is a glycoprotein that functions as a coreceptor for the T-cell receptor (TCR) [92]. The production of interleukin (IL)-1 and other cytokines by monocytes, macrophages, cancer cells, and fibroblasts was connected to the development of tumor-related immunosuppression, which might explain why IL-1 is associated with the development of COAD, and investigating this immune cell infiltration is critical [93]. The presence of heavy infiltration of tumor-infiltrating lymphocytes (TILs) in tumors, particularly $\mathrm{CD}^{+}$and $\mathrm{CD} 8^{+} \mathrm{T}$ cells, was linked to a favorable clinical prognosis for patients, as seen by prolonged progression-free survival (PFS) and OS [94-97].

We discovered a link between FABP6 expression and insulin-like growth factor (IGF) signaling in CRC. FABP6 expression was also linked to nearly all clinicopathologic variables and was associated with a worse outcome in CRC patients with a p53 mutation. FABP6 overexpression results in an increase in the abundance of interleukin (IL)- 1 and IL-6. IL-1 is a powerful proinflammatory cytokine that plays a key protective role against infection and damage [98]. Inflammation, immunological responses, and hematopoiesis are all influenced by IL-6 [99]. As part of the inflammatory response, its signaling reduces IGFbinding protein 4 (IBP4) and IBP2 protein production. These two genes belong to the IBP family of protein-coding genes. Inflammation and cytokine production by visceral adipose tissues might lead to alternations of inhibitor of nuclear factor- $\kappa \mathrm{B} \beta(\mathrm{I} \kappa \mathrm{B} \beta)$ and peroxisome proliferator-activated receptor (PPAR) signaling, which are potential therapeutic targets for insulin resistance and chemoprevention of CRC. Diseases associated with the IGF signaling pathway include CRC [100]. The IGF signaling pathway is a complicated and tightly controlled network that is essential for cell proliferation and survival [101]. According to some studies, high levels of IGF1 in circulation and an elevated IGF1/IGFBP3 ratio 
disrupt growth hormone (GH)/IGF1 balance, which might be a sign of cancer risk [102]. GRB10, PIK3R3, PIK3R1, and IRS1 were identified as differentiating transcripts in two investigations of expression patterns of genes encoding proteins of signaling cascades triggered by IGFs in CRC [103,104].

According to previous research, FABP4 was implicated in metabolic balance and inflammatory disorders [105-107]. FABP4, also known as adipocyte FABP (AFABP) or adipocyte $\mathrm{P} 2(\mathrm{aP} 2)$, is a small cytoplasmic FABP that is produced by macrophages, adipose tissues, and mature adipocytes. According to Zhang et al., serum FABP4 and FABP6 levels in Chinese patients can possibly be used as biomarkers for CRC diagnoses. FABP4 and FABP6 serum levels were substantially higher in CRC patients, and elevated FABP4 and FABP6 expression was linked to the development of CRC, according to their findings [108]. In our study, we found that overexpression of FABP4 and FABP6 were also related to a poor CRC OS prognosis.

Correlations between FABPs levels and clinical parameters, such as age, body-mass index (BMI), waist circumference, high-density lipoprotein (HDL) cholesterol, low-density lipoprotein (LDL) cholesterol, total cholesterol, systolic blood pressure, diastolic blood pressure, triglycerides, glucose, insulin, homeostasis model asssessmeent of insulin resistance (HOMA-R) (an indicator of insulin resistance), estimated glomerular filtration rate (eGFR), alanine aminotransferase (ALT), aspartate transaminase (AST), high sensitivity Creactive protein (hsCRP), and brain natriuretic peptide (BNP), were previously investigated. According to a recent study, compared to normal conditions, increased FABP tissue concentrations and serum level concentrations make FABP serum levels unique and sensitive. However, that study only measured the concentrations and serum levels of FABP1-5 [109]. In this present study, FABP6 mRNA expression was found to be significantly higher in the progression from normal tissues to adenomas and CRC. We hypothesize that FABP6 overexpression in cancer cells is linked to early-stage carcinogenesis, but it is not required for late-stage cancer progression. Lastly, we assessed the biological role of overexpression of the FABP6 gene in colorectal malignancies. Our results showed that FABP6 could be a potential biomarker for CRC.

\section{Conclusions}

Our study showed that FABP6 is overexpressed in CRC patients and is related to a poor prognosis in terms of overall survival prognosis. Through an enrichment pathway, we found that $F A B P 6$ has an important role in early CRC as it was correlated with miRNAs linked to cell proliferation in the IGF pathway in CRC. In conclusion, FABP6 could possibly serve as a potential prognostic biomarker and therapeutic target in CRC.

Supplementary Materials: The following are available online at https:/ / www.mdpi.com/article/ 10.3390/biomedicines9101460/s1: Figure S1: Correlations between differentially expressed fatty acid-binding protein $(F A B P)$ genes and immune cell infiltration in primary colorectal cancer (CRC) patients (A-F) (TIMER), Figure S2: Fatty acid-binding protein 1 (FABP1) differentially expressed gene pathways in colorectal cancer (CRC) developed by MetaCore. "Transcription_HIF-1 targets" were correlated with CRC development, Figure S3: Fatty acid-binding protein 2 (FABP2) differentially expressed gene pathways in colorectal cancer (CRC) developed by MetaCore. "PXR-mediated direct regulation of xenobiotic metabolizing enzymes human version" was correlated with CRC development, Figure S4: Fatty acid-binding protein 3 (FABP3) differentially expressed gene pathways in colorectal cancer (CRC) developed by MetaCore. "Immune response_Immunological synapse formation" was correlated with CRC development, Figure S5: Fatty acid-binding protein 4 (FABP4) differentially expressed gene pathways in colorectal cancer (CRC) developed by MetaCore. "Immune response_lectin-induced complement pathway" was correlated with CRC development, Figure S6: Fatty acid-binding protein 5 (FABP5) differentially expressed gene pathways in colorectal cancer (CRC) developed by MetaCore. "DNA damage_intra S-phase checkpoint" was correlated with CRC development, Figure S7: Fatty acid-binding protein 7 (FABP7) differentially expressed gene pathways in colorectal cancer (CRC) developed by MetaCore. "Immune response_IL-12 signaling pathway" was correlated with CRC development, Figure S8: Fatty acid-binding protein 9 (FABP9) 
differentially expressed gene pathways in colorectal cancer (CRC) developed by MetaCore. "Putative role of Tregs in COPD" was correlated with CRC development, Figure S9: Fatty acid-binding protein 12 (FABP12) differentially expressed gene pathways in colorectal cancer (CRC) developed by MetaCore. "Development_TGF-beta-dependent induction of EMT via MAPK" was correlated with CRC development, Table S1: Prognostic value of fatty acid-binding proteins (FABPs) in colorectal cancer (CRC) (PrognoScan database) (Cox $p<0.05)$, Table S2: FABP1 differentially expressed genes pathway in CRC developed by MetaCore. Transcription_HIF-1 targets were correlated with CRC development, Table S3: FABP2 differentially expressed genes pathway in CRC developed by MetaCore. PXR-mediated direct regulation of xenobiotic metabolizing enzymes human version was correlated with CRC development, Table S4: FABP3 differentially expressed genes pathway in CRC developed by MetaCore. Immune response_immunological synapse formation was correlated with CRC development, Table S5: FABP4 differentially expressed genes pathway in CRC developed by MetaCore. Immune response_lectin-induced complement pathway was correlated with CRC development, Table S6: FABP5 differentially expressed genes pathway in CRC developed by MetaCore. DNA damage_intra S-phase checkpoint was correlated with CRC development, Table S7: FABP6 differentially expressed genes pathway in CRC developed by MetaCore. Role of microRNAs in cell proliferation in colorectal cancer was correlated with CRC development, Table S8: FABP7 differentially expressed genes pathway in CRC developed by MetaCore. Immune response_IL-12 signaling pathway was correlated with CRC development, Table S9: FABP9 differentially expressed genes pathway in CRC developed by MetaCore. Putative role of Tregs in COPD was correlated with CRC development, Table S10: FABP12 differentially expressed genes pathway in CRC developed by MetaCore. Development_TGF-beta-dependent induction of EMT via MAPK was correlated with CRC development.

Author Contributions: F.B.P., T.-J.K., G.A., H.D.K.T., L.-C.L., J.-Y.C., and Y.-F.W. conceptualized the project, performed the bioinformatics analysis, and wrote the manuscript. C.-Y.W. and K.-H.L. performed the data analysis and revised the manuscript. All authors contributed to the article and approved the submitted version. All authors have read and agreed to the published version of the manuscript.

Funding: The study was supported by grants from the Ministry of Science and Technology (MOST) of Taiwan (MOST 110-2320-B-038-017-MY3 to T.J.K., MOST109-2320-B-038-009-MY2 to C.Y.W., and MOST 110-2636-B-038-004 to J.Y.C.) and from the Ministry of Health and Welfare Surcharge of Education Tobacco Products of Taiwan (Wan-Fang Hospital, Chi-Mei Medical Center, and Hualien Tzu-Chi Hospital Joint Cancer Center Grant-Focus on Colon Cancer Research; DP2-109-21121-03-C03-03 and MOHW110-TDU-B-212-144020 awarded to K.H.L.), as well as the "TMU Research Center of Cancer Translational Medicine" from The Featured Areas Research Center Program within the framework of the Higher Education Sprout Project by the Ministry of Education (MOE) in Taiwan.

Institutional Review Board Statement: Not applicable.

Informed Consent Statement: Not applicable.

Acknowledgments: The authors truly appreciate Daniel P. Chamberlin from the Office of Research and Development at Taipei Medical University for professional English editing. The authors acknowledge the statistical/computational/technical support of the Clinical Data Center, Office of Data Science, Taipei Medical University, Taiwan.

Conflicts of Interest: The authors declare no conflict of interest. The funders had no role in the design of the study; in the collection, analyses, or interpretation of data; in the writing of the manuscript, or in the decision to publish the results.

\section{Abbreviations}

FABPs, fatty-acid binding proteins; CRC, colorectal cancer; COAD, colon adenocarcinoma; READ, rectal adenocarcinoma; CCLE, Cancer Cell Line Encyclopedia; GEPIA, Gene Expression Profiling Interactive Analysis; STRING, Search Tool for the Retrieval of Interacting Genes/Proteins; TIMER, Tumor Immune Estimation Resource; OS, overall survival. 


\section{References}

1. Sung, H.; Ferlay, J.; Siegel, R.L.; Laversanne, M.; Soerjomataram, I.; Jemal, A.; Bray, F. Global Cancer Statistics 2020: GLOBOCAN Estimates of Incidence and Mortality Worldwide for 36 Cancers in 185 Countries. CA Cancer J. Clin. 2021, 71, 209-249. [CrossRef]

2. Center, M.M.; Jemal, A.; Smith, R.A.; Ward, E. Worldwide variations in colorectal cancer. CA Cancer J. Clin. 2009, 59, 366-378. [CrossRef]

3. Haunerland, N.H.; Spener, F. Fatty acid-binding proteins-Insights from genetic manipulations. Prog. Lipid Res. 2004, 43, 328-349. [CrossRef] [PubMed]

4. Zeng, X.; Ye, H.; Yang, Y.; Wang, G.; Huang, H. Molecular cloning and functional analysis of the fatty acid-binding protein (Sp-FABP) gene in the mud crab (Scylla paramamosain). Genet. Mol. Biol. 2013, 36, 140-147. [CrossRef]

5. Zhang, G.; Fang, X.; Guo, X.; Li, L.; Luo, R.; Xu, F.; Yang, P.; Zhang, L.; Wang, X.; Qi, H.; et al. The oyster genome reveals stress adaptation and complexity of shell formation. Nature 2012, 490, 49-54. [CrossRef]

6. Chmurzyńska, A. The multigene family of fatty acid-binding proteins (FABPs): Function, structure and polymorphism. J. Appl. Genet. 2006, 47, 39-48. [CrossRef] [PubMed]

7. Mishkin, S.; Stein, L.; Gatmaitan, Z.; Arias, I.M. The binding of fatty acids to cytoplasmic proteins: Binding to Z protein in liver and other tissues of the rat. Biochem. Biophys. Res. Commun. 1972, 47, 997-1003. [CrossRef]

8. Storch, J.; Thumser, A.E. Tissue-specific functions in the fatty acid-binding protein family. J. Biol. Chem. 2010, 285, 32679-32683. [CrossRef]

9. Chen, X.; Hu, S.L.; Feng, Y.; Li, P.; Mao, Q.S.; Xue, W.J. Expression of Fatty Acid-Binding Protein-3 in Gastrointestinal Stromal Tumors and Its Significance for Prognosis. J. Surg. Res. 2021, 260, 462-466. [CrossRef]

10. Bao, Z.; Malki, M.I.; Forootan, S.S.; Adamson, J.; Forootan, F.S.; Chen, D.; Foster, C.S.; Rudland, P.S.; Ke, Y. A novel cutaneous Fatty Acid-binding protein-related signaling pathway leading to malignant progression in prostate cancer cells. Genes Cancer 2013, 4, 297-314. [CrossRef]

11. Al Fayi, M.S.; Gou, X.; Forootan, S.S.; Al-Jameel, W.; Bao, Z.; Rudland, P.R.; Cornford, P.A.; Hussain, S.A.; Ke, Y. The increased expression of fatty acid-binding protein 9 in prostate cancer and its prognostic significance. Oncotarget 2016, 7, 82783-82797. [CrossRef]

12. Nagao, K.; Shinohara, N.; Smit, F.; de Weijert, M.; Jannink, S.; Owada, Y.; Mulders, P.; Oosterwijk, E.; Matsuyama, H. Fatty acid binding protein 7 may be a marker and therapeutic targets in clear cell renal cell carcinoma. BMC Cancer 2018, 18, 1114. [CrossRef]

13. Imray, C.H.; Radley, S.; Davis, A.; Barker, G.; Hendrickse, C.W.; Donovan, I.A.; Lawson, A.M.; Baker, P.R.; Neoptolemos, J.P. Faecal unconjugated bile acids in patients with colorectal cancer or polyps. Gut 1992, 33, 1239-1245. [CrossRef]

14. Fujii, H.; Nomura, M.; Kanda, T.; Amano, O.; Iseki, S.; Hatakeyama, K.; Ono, T. Cloning of a cDNA encoding rat intestinal 15 kDa protein and its tissue distribution. Biochem. Biophys. Res. Commun. 1993, 190, 175-180. [CrossRef] [PubMed]

15. Venturi, M.; Hambly, R.J.; Glinghammar, B.; Rafter, J.J.; Rowland, I.R. Genotoxic activity in human faecal water and the role of bile acids: A study using the alkaline comet assay. Carcinogenesis 1997, 18, 2353-2359. [CrossRef]

16. Cao, Y.; Deng, S.; Yan, L.; Gu, J.; Yang, J.; Yang, M.; Liu, L.; Cai, K. A nomogram based on pretreatment levels of serum bilirubin and total bile acid levels predicts survival in colorectal cancer patients. BMC Cancer 2021, 21, 85. [CrossRef] [PubMed]

17. Uchiyama, K.; Naito, Y.; Yagi, N.; Mizushima, K.; Higashimura, Y.; Hirai, Y.; Dohi, O.; Okayama, T.; Yoshida, N.; Katada, K.; et al. Identification of colorectal neoplasia by using serum bile acid profile. Biomarkers 2021, 26, 462-467. [CrossRef] [PubMed]

18. Ohmachi, T.; Inoue, H.; Mimori, K.; Tanaka, F.; Sasaki, A.; Kanda, T.; Fujii, H.; Yanaga, K.; Mori, M. Fatty acid binding protein 6 is overexpressed in colorectal cancer. Clin. Cancer Res. 2006, 12, 5090-5095. [CrossRef]

19. Sever, R.; Brugge, J.S. Signal transduction in cancer. Cold Spring Harb. Perspect. Med. 2015, 5, a006098. [CrossRef]

20. Chakravarthi, B.V.; Nepal, S.; Varambally, S. Genomic and Epigenomic Alterations in Cancer. Am. J. Pathol. 2016, 186, 1724-1735. [CrossRef]

21. Herceg, Z.; Hainaut, P. Genetic and epigenetic alterations as biomarkers for cancer detection, diagnosis and prognosis. Mol. Oncol. 2007, 1, 26-41. [CrossRef]

22. Barrett, T.; Wilhite, S.E.; Ledoux, P.; Evangelista, C.; Kim, I.F.; Tomashevsky, M.; Marshall, K.A.; Phillippy, K.H.; Sherman, P.M.; Holko, M.; et al. NCBI GEO: Archive for functional genomics data sets-Update. Nucleic Acids Res. 2013, 41, D991-D995. [CrossRef] [PubMed]

23. Lin, J.C.; Liu, T.P.; Yang, P.M. CDKN2A-Inactivated Pancreatic Ductal Adenocarcinoma Exhibits Therapeutic Sensitivity to Paclitaxel: A Bioinformatics Study. J. Clin. Med. 2020, 9, 4019. [CrossRef]

24. Lin, T.Y.; Wang, P.W.; Huang, C.H.; Yang, P.M.; Pan, T.L. Characterizing the Relapse Potential in Different Luminal Subtypes of Breast Cancers with Functional Proteomics. Int. J. Mol. Sci. 2020, 21, 6077. [CrossRef] [PubMed]

25. Liu, L.W.; Hsieh, Y.Y.; Yang, P.M. Bioinformatics Data Mining Repurposes the JAK2 (Janus Kinase 2) Inhibitor Fedratinib for Treating Pancreatic Ductal Adenocarcinoma by Reversing the KRAS (Kirsten Rat Sarcoma 2 Viral Oncogene Homolog)-Driven Gene Signature. J. Pers. Med. 2020, 10, 130. [CrossRef] [PubMed]

26. Yang, P.M.; Hsieh, Y.Y.; Du, J.L.; Yen, S.C.; Hung, C.F. Sequential Interferon $\beta$-Cisplatin Treatment Enhances the Surface Exposure of Calreticulin in Cancer Cells via an Interferon Regulatory Factor 1-Dependent Manner. Biomolecules 2020, 10, 643. [CrossRef] [PubMed]

27. Yang, P.M.; Lin, L.S.; Liu, T.P. Sorafenib Inhibits Ribonucleotide Reductase Regulatory Subunit M2 (RRM2) in Hepatocellular Carcinoma Cells. Biomolecules 2020, 10, 117. [CrossRef] [PubMed] 
28. Thorat, M.A.; Balasubramanian, R. Breast cancer prevention in high-risk women. Best Pract. Res. Clin. Obstet. Gynaecol. 2020, 65, 18-31. [CrossRef] [PubMed]

29. Lin, C.Y.; Lee, C.H.; Chuang, Y.H.; Lee, J.Y.; Chiu, Y.Y.; Wu Lee, Y.H.; Jong, Y.J.; Hwang, J.K.; Huang, S.H.; Chen, L.C.; et al. Membrane protein-regulated networks across human cancers. Nat. Commun. 2019, 10, 3131. [CrossRef] [PubMed]

30. Tsai, H.T.; Huang, C.S.; Tu, C.C.; Liu, C.Y.; Huang, C.J.; Ho, Y.S.; Tu, S.H.; Tseng, L.M.; Huang, C.C. Multi-gene signature of microcalcification and risk prediction among Taiwanese breast cancer. Sci. Rep. 2020, 10, 18276. [CrossRef]

31. Nguyen, H.D.; Liao, Y.C.; Ho, Y.S.; Chen, L.C.; Chang, H.W.; Cheng, T.C.; Liu, D.; Lee, W.R.; Shen, S.C.; Wu, C.H.; et al. The $\alpha 9$ Nicotinic Acetylcholine Receptor Mediates Nicotine-Induced PD-L1 Expression and Regulates Melanoma Cell Proliferation and Migration. Cancers 2019, 11, 1991. [CrossRef] [PubMed]

32. Lee, K.L.; Kuo, Y.C.; Ho, Y.S.; Huang, Y.H. Triple-Negative Breast Cancer: Current Understanding and Future Therapeutic Breakthrough Targeting Cancer Stemness. Cancers 2019, 11, 1334. [CrossRef]

33. Rhodes, D.R.; Yu, J.; Shanker, K.; Deshpande, N.; Varambally, R.; Ghosh, D.; Barrette, T.; Pandey, A.; Chinnaiyan, A.M. ONCOMINE: A cancer microarray database and integrated data-mining platform. Neoplasia 2004, 6, 1-6. [CrossRef]

34. Li, C.; Tang, Z.; Zhang, W.; Ye, Z.; Liu, F. GEPIA2021: Integrating multiple deconvolution-based analysis into GEPIA. Nucleic Acids Research 2021, 49, W242-W246. [CrossRef]

35. Barretina, J.; Caponigro, G.; Stransky, N.; Venkatesan, K.; Margolin, A.A.; Kim, S.; Wilson, C.J.; Lehár, J.; Kryukov, G.V.; Sonkin, D.; et al. The Cancer Cell Line Encyclopedia enables predictive modelling of anticancer drug sensitivity. Nature 2012, 483, 603-607. [CrossRef] [PubMed]

36. Wang, C.Y.; Li, C.Y.; Hsu, H.P.; Cho, C.Y.; Yen, M.C.; Weng, T.Y.; Chen, W.C.; Hung, Y.H.; Lee, K.T.; Hung, J.H.; et al. PSMB5 plays a dual role in cancer development and immunosuppression. Am. J. Cancer Res. 2017, 7, 2103-2120.

37. Shahi, P.; Wang, C.Y.; Lawson, D.A.; Slorach, E.M.; Lu, A.; Yu, Y.; Lai, M.D.; Gonzalez Velozo, H.; Werb, Z. ZNF503/Zpo2 drives aggressive breast cancer progression by down-regulation of GATA3 expression. Proc. Natl. Acad. Sci. USA 2017, 114, 3169-3174. [CrossRef] [PubMed]

38. Cooke, D.L.; McCoy, D.B.; Halbach, V.V.; Hetts, S.W.; Amans, M.R.; Dowd, C.F.; Higashida, R.T.; Lawson, D.; Nelson, J.; Wang, C.Y.; et al. Endovascular Biopsy: In Vivo Cerebral Aneurysm Endothelial Cell Sampling and Gene Expression Analysis. Transl. Stroke Res. 2018, 9, 20-33. [CrossRef]

39. Weng, T.Y.; Wu, H.F.; Li, C.Y.; Hung, Y.H.; Chang, Y.W.; Chen, Y.L.; Hsu, H.P.; Chen, Y.H.; Wang, C.Y.; Chang, J.Y.; et al. Homoharringtonine induced immune alteration for an Efficient Anti-tumor Response in Mouse Models of Non-small Cell Lung Adenocarcinoma Expressing Kras Mutation. Sci. Rep. 2018, 8, 8216. [CrossRef]

40. Cho, C.Y.; Lee, K.T.; Chen, W.C.; Wang, C.Y.; Chang, Y.S.; Huang, H.L.; Hsu, H.P.; Yen, M.C.; Lai, M.Z.; Lai, M.D. MST3 promotes proliferation and tumorigenicity through the VAV2/Rac1 signal axis in breast cancer. Oncotarget 2016, 7, 14586-14604. [CrossRef]

41. Huang, H.L.; Chen, W.C.; Hsu, H.P.; Cho, C.Y.; Hung, Y.H.; Wang, C.Y.; Lai, M.D. Argininosuccinate lyase is a potential therapeutic target in breast cancer. Oncol. Rep. 2015, 34, 3131-3139. [CrossRef]

42. Weng, T.Y.; Huang, S.S.; Yen, M.C.; Lin, C.C.; Chen, Y.L.; Lin, C.M.; Chen, W.C.; Wang, C.Y.; Chang, J.Y.; Lai, M.D. A novel cancer therapeutic using thrombospondin 1 in dendritic cells. Mol. Ther. 2014, 22, 292-302. [CrossRef] [PubMed]

43. Phan, N.N.; Wang, C.Y.; Lin, Y.C. The novel regulations of MEF2A, CAMKK2, CALM3, and TNNI3 in ventricular hypertrophy induced by arsenic exposure in rats. Toxicology 2014, 324, 123-135. [CrossRef]

44. Uhlen, M.; Fagerberg, L.; Hallstrom, B.M.; Lindskog, C.; Oksvold, P.; Mardinoglu, A.; Sivertsson, A.; Kampf, C.; Sjostedt, E.; Asplund, A.; et al. Proteomics. Tissue-based map of the human proteome. Science 2015, 347, 1260419. [CrossRef] [PubMed]

45. Uhlén, M.; Björling, E.; Agaton, C.; Szigyarto, C.A.; Amini, B.; Andersen, E.; Andersson, A.C.; Angelidou, P.; Asplund, A.; Asplund, C.; et al. A human protein atlas for normal and cancer tissues based on antibody proteomics. Mol. Cell Proteom. 2005, 4, 1920-1932. [CrossRef] [PubMed]

46. Mizuno, H.; Kitada, K.; Nakai, K.; Sarai, A. PrognoScan: A new database for meta-analysis of the prognostic value of genes. BMC Med. Genom. 2009, 2, 18. [CrossRef] [PubMed]

47. Chen, P.Y.; Chao, T.Y.; Hsu, H.J.; Wang, C.Y.; Lin, C.Y.; Gao, W.Y.; Wu, M.J.; Yen, J.H. The Lipid-Modulating Effect of Tangeretin on the Inhibition of Angiopoietin-like 3 (ANGPTL3) Gene Expression through Regulation of LXR $\alpha$ Activation in Hepatic Cells. Int. J. Mol. Sci. 2021, 22, 9853. [CrossRef] [PubMed]

48. Choy, T.K.; Wang, C.Y.; Phan, N.N.; Khoa Ta, H.D.; Anuraga, G.; Liu, Y.H.; Wu, Y.F.; Lee, K.H.; Chuang, J.Y.; Kao, T.J. Identification of Dipeptidyl Peptidase (DPP) Family Genes in Clinical Breast Cancer Patients via an Integrated Bioinformatics Approach. Diagnostics 2021, 11, 1204. [CrossRef]

49. Kao, T.J.; Wu, C.C.; Phan, N.N.; Liu, Y.H.; Ta, H.D.K.; Anuraga, G.; Wu, Y.F.; Lee, K.H.; Chuang, J.Y.; Wang, C.Y. Prognoses and genomic analyses of proteasome 26S subunit, ATPase (PSMC) family genes in clinical breast cancer. Aging 2021, 13, 17970. [CrossRef] [PubMed]

50. Khoa Ta, H.D.; Tang, W.C.; Phan, N.N.; Anuraga, G.; Hou, S.Y.; Chiao, C.C.; Liu, Y.H.; Wu, Y.F.; Lee, K.H.; Wang, C.Y. Analysis of LAGEs Family Gene Signature and Prognostic Relevance in Breast Cancer. Diagnostics 2021, 11, 726. [CrossRef]

51. Chen, P.S.; Hsu, H.P.; Phan, N.N.; Yen, M.C.; Chen, F.W.; Liu, Y.W.; Lin, F.P.; Feng, S.Y.; Cheng, T.L.; Yeh, P.H.; et al. CCDC167 as a potential therapeutic target and regulator of cell cycle-related networks in breast cancer. Aging 2021, 13, 4157-4181. [CrossRef] [PubMed] 
52. Wu, P.S.; Yen, J.H.; Wang, C.Y.; Chen, P.Y.; Hung, J.H.; Wu, M.J. 8-Hydroxydaidzein, an Isoflavone from Fermented Soybean, Induces Autophagy, Apoptosis, Differentiation, and Degradation of Oncoprotein BCR-ABL in K562 Cells. Biomedicines 2020, 8 , 506. [CrossRef] [PubMed]

53. Szklarczyk, D.; Gable, A.L.; Lyon, D.; Junge, A.; Wyder, S.; Huerta-Cepas, J.; Simonovic, M.; Doncheva, N.T.; Morris, J.H.; Bork, P.; et al. STRING v11: Protein-protein association networks with increased coverage, supporting functional discovery in genome-wide experimental datasets. Nucleic Acids Res. 2019, 47, D607-D613. [CrossRef] [PubMed]

54. Szklarczyk, D.; Morris, J.H.; Cook, H.; Kuhn, M.; Wyder, S.; Simonovic, M.; Santos, A.; Doncheva, N.T.; Roth, A.; Bork, P.; et al. The STRING database in 2017: Quality-controlled protein-protein association networks, made broadly accessible. Nucleic Acids Res. 2017, 45, D362-D368. [CrossRef]

55. Gao, J.; Aksoy, B.A.; Dogrusoz, U.; Dresdner, G.; Gross, B.; Sumer, S.O.; Sun, Y.; Jacobsen, A.; Sinha, R.; Larsson, E.; et al. Integrative Analysis of Complex Cancer Genomics and Clinical Profiles Using the cBioPortal. Sci. Signal. 2013, 6, pl1. [CrossRef]

56. Jiang, H.-H.; Zhang, Z.-Y.; Wang, X.-Y.; Tang, X.; Liu, H.-L.; Wang, A.-L.; Li, H.-G.; Tang, E.-J.; Lin, M.-B. Prognostic significance of lymphovascular invasion in colorectal cancer and its association with genomic alterations. World J. Gastroenterol. 2019, 25, 2489-2502. [CrossRef]

57. Udhaya Kumar, S.; Madhana Priya, N.; Thirumal Kumar, D.; Anu Preethi, V.; Kumar, V.; Nagarajan, D.; Magesh, R.; Younes, S.; Zayed, H.; George Priya Doss, C. An integrative analysis to distinguish between emphysema (EML) and alpha-1 antitrypsin deficiency-related emphysema (ADL)-A systems biology approach. Adv. Protein Chem. Struct. Biol. 2021, 127, 315-342. [CrossRef]

58. Bai, Y.; Tong, W.; Xie, F.; Zhu, L.; Wu, H.; Shi, R.; Wang, L.; Yang, L.; Liu, Z.; Miao, F.; et al. DNA methylation biomarkers for diagnosis of primary liver cancer and distinguishing hepatocellular carcinoma from intrahepatic cholangiocarcinoma. Aging 2021, 13, 17592-17606. [CrossRef]

59. Romero-Pimentel, A.L.; Almeida, D.; Munoz-Montero, S.; Rangel, C.; Mendoza-Morales, R.; Gonzalez-Saenz, E.E.; Nagy, C.; Chen, G.; Aouabed, Z.; Theroux, J.F.; et al. Integrative DNA Methylation and Gene Expression Analysis in the Prefrontal Cortex of Mexicans who died by Suicide. Int. J. Neuropsychopharmacol. 2021. online ahead of print. [CrossRef]

60. Wang, C.Y.; Chao, Y.J.; Chen, Y.L.; Wang, T.W.; Phan, N.N.; Hsu, H.P.; Shan, Y.S.; Lai, M.D. Upregulation of peroxisome proliferator-activated receptor- $\alpha$ and the lipid metabolism pathway promotes carcinogenesis of ampullary cancer. Int. J. Med. Sci. 2021, 18, 256-269. [CrossRef]

61. Lin, Y.Y.; Wang, C.Y.; Phan, N.N.; Chiao, C.C.; Li, C.Y.; Sun, Z.; Hung, J.H.; Chen, Y.L.; Yen, M.C.; Weng, T.Y.; et al. PODXL2 maintains cellular stemness and promotes breast cancer development through the Rac1/Akt pathway. Int. J. Med. Sci. 2020, 17, 1639-1651. [CrossRef]

62. Liu, H.L.; Yeh, I.J.; Phan, N.N.; Wu, Y.H.; Yen, M.C.; Hung, J.H.; Chiao, C.C.; Chen, C.F.; Sun, Z.; Jiang, J.Z.; et al. Gene signatures of SARS-CoV/SARS-CoV-2-infected ferret lungs in short- and long-term models. Infect. Genet. Evol. 2020, 85, 104438. [CrossRef] [PubMed]

63. Phan, N.N.; Liu, S.; Wang, C.Y.; Hsu, H.P.; Lai, M.D.; Li, C.Y.; Chen, C.F.; Chiao, C.C.; Yen, M.C.; Sun, Z.; et al. Overexpressed gene signature of $\mathrm{EPH}$ receptor $\mathrm{A} / \mathrm{B}$ family in cancer patients-comprehensive analyses from the public high-throughput database. Int. J. Clin. Exp. Pathol. 2020, 13, 1220-1242.

64. Li, T.; Fu, J.; Zeng, Z.; Cohen, D.; Li, J.; Chen, Q.; Li, B.; Liu, X.S. TIMER2.0 for analysis of tumor-infiltrating immune cells. Nucleic Acids Res. 2020, 48, W509-W514. [CrossRef]

65. Li, T.; Fan, J.; Wang, B.; Traugh, N.; Chen, Q.; Liu, J.S.; Li, B.; Liu, X.S. TIMER: A Web Server for Comprehensive Analysis of Tumor-Infiltrating Immune Cells. Cancer Res. 2017, 77, e108-e110. [CrossRef]

66. Li, B.; Severson, E.; Pignon, J.C.; Zhao, H.; Li, T.; Novak, J.; Jiang, P.; Shen, H.; Aster, J.C.; Rodig, S.; et al. Comprehensive analyses of tumor immunity: Implications for cancer immunotherapy. Genome Biol. 2016, 17, 174. [CrossRef]

67. Huang, H.; Starodub, O.; McIntosh, A.; Kier, A.B.; Schroeder, F. Liver fatty acid-binding protein targets fatty acids to the nucleus. Real time confocal and multiphoton fluorescence imaging in living cells. J. Biol. Chem. 2002, 277, 29139-29151. [CrossRef]

68. Jung, D.; Fried, M.; Kullak-Ublick, G.A. Human apical sodium-dependent bile salt transporter gene (SLC10A2) is regulated by the peroxisome proliferator-activated receptor alpha. J. Biol. Chem. 2002, 277, 30559-30566. [CrossRef]

69. de Aguiar Vallim, T.Q.; Tarling, E.J.; Edwards, P.A. Pleiotropic roles of bile acids in metabolism. Cell Metab. 2013, 17, 657-669. [CrossRef]

70. Luceri, C.; Femia, A.P.; D'Ambrosio, M.; Caderni, G. High Sensitivity to Cholic Acid-induced Colonic Tumorigenesis Makes Female PIRC Rats (F344/NTac-Apc(am1137)) a Suitable Model for Studying CRC-promoting Agents. Anticancer Res. 2019, 39, 4673-4679. [CrossRef]

71. Bailey, A.M.; Zhan, L.; Maru, D.; Shureiqi, I.; Pickering, C.R.; Kiriakova, G.; Izzo, J.; He, N.; Wei, C.; Baladandayuthapani, V.; et al. FXR silencing in human colon cancer by DNA methylation and KRAS signaling. Am. J. Physiol. Gastrointest. Liver Physiol. 2014, 306, G48-G58. [CrossRef] [PubMed]

72. Meng, Q.; Luo, Z.; Cao, C.; Sun, S.; Ma, Q.; Li, Z.; Shi, B.; Shan, A. Weaning Alters Intestinal Gene Expression Involved in Nutrient Metabolism by Shaping Gut Microbiota in Pigs. Front. Microbiol. 2020, 11, 694. [CrossRef]

73. Wang, Y.; Huang, L.; Shan, N.; Ma, H.; Lu, S.; Chen, X.; Long, H. Establishing a three-miRNA signature as a prognostic model for colorectal cancer through bioinformatics analysis. Aging 2021, 13, 19894-19907. [CrossRef] [PubMed]

74. Jafarzadeh, M.; Soltani, B.M. MiRNA-Wnt signaling regulatory network in colorectal cancer. J. Biochem. Mol. Toxicol. 2021, e22883. [CrossRef] 
75. Ebadfardzadeh, J.; Kazemi, M.; Aghazadeh, A.; Rezaei, M.; Shirvaliloo, M.; Sheervalilou, R. Employing bioinformatics analysis to identify hub genes and microRNAs involved in colorectal cancer. Med. Oncol. 2021, 38, 114. [CrossRef] [PubMed]

76. Liu, Y.; Zhang, Y.; Wu, H.; Li, Y.; Zhang, Y.; Liu, M.; Li, X.; Tang, H. miR-10a suppresses colorectal cancer metastasis by modulating the epithelial-to-mesenchymal transition and anoikis. Cell Death Dis. 2017, 8, e2739. [CrossRef]

77. Guo, L.; Fu, J.; Sun, S.; Zhu, M.; Zhang, L.; Niu, H.; Chen, Z.; Zhang, Y.; Guo, L.; Wang, S. MicroRNA-143-3p inhibits colorectal cancer metastases by targeting ITGA6 and ASAP3. Cancer Sci. 2019, 110, 805-816. [CrossRef] [PubMed]

78. Kong, B.; Zhao, S.; Kang, X.; Wang, B. MicroRNA-133a-3p inhibits cell proliferation, migration and invasion in colorectal cancer by targeting AQP1. Oncol. Lett. 2021, 22, 649. [CrossRef] [PubMed]

79. Zheng, J.; Yang, T.; Gao, S.; Cheng, M.; Shao, Y.; Xi, Y.; Guo, L.; Zhang, D.; Gao, W.; Zhang, G.; et al. miR-148a-3p silences the CANX/MHC-I pathway and impairs CD8(+) T cell-mediated immune attack in colorectal cancer. FASEB J. 2021, 35, e21776. [CrossRef]

80. Makowski, L.; Hotamisligil, G.S. Fatty acid binding proteins-the evolutionary crossroads of inflammatory and metabolic responses. J. Nutr. 2004, 134, 2464S-2468S. [CrossRef]

81. Furuhashi, M.; Fucho, R.; Gorgun, C.Z.; Tuncman, G.; Cao, H.; Hotamisligil, G.S. Adipocyte/macrophage fatty acid-binding proteins contribute to metabolic deterioration through actions in both macrophages and adipocytes in mice. J. Clin. Investig. 2008, 118, 2640-2650. [CrossRef] [PubMed]

82. Hsieh, I.S.; Chang, K.C.; Tsai, Y.T.; Ke, J.Y.; Lu, P.J.; Lee, K.H.; Yeh, S.D.; Hong, T.M.; Chen, Y.L. MicroRNA-320 suppresses the stem cell-like characteristics of prostate cancer cells by downregulating the Wnt/beta-catenin signaling pathway. Carcinogenesis 2013, 34, 530-538. [CrossRef]

83. Mackay, C.; Nathke, I.; Appleton, P. beta-Catenin Complexes in Colorectal Cancer and Their Functional Implications. Gastroenterology 2015, 148, S932. [CrossRef]

84. Wu, Y.F.; Wang, C.Y.; Tang, W.C.; Lee, Y.C.; Ta, H.D.K.; Lin, L.C.; Pan, S.R.; Ni, Y.C.; Anuraga, G.; Lee, K.H. Expression Profile and Prognostic Value of Wnt Signaling Pathway Molecules in Colorectal Cancer. Biomedicines 2021, 9, 1331. [CrossRef]

85. Shibutani, M.; Nakao, S.; Maeda, K.; Nagahara, H.; Kashiwagi, S.; Hirakawa, K.; Ohira, M. The Impact of Tumor-associated Macrophages on Chemoresistance via Angiogenesis in Colorectal Cancer. Anticancer Res. 2021, 41, 4447-4453. [CrossRef]

86. Wang, H.; Tian, T.; Zhang, J. Tumor-Associated Macrophages (TAMs) in Colorectal Cancer (CRC): From Mechanism to Therapy and Prognosis. Int. J. Mol. Sci. 2021, 22, 8470. [CrossRef]

87. Dou, X.; Wang, R.B.; Yan, H.J.; Jiang, S.M.; Meng, X.J.; Zhu, K.L.; Xu, X.Q.; Mu, D.B. Circulating lymphocytes as predictors of sensitivity to preoperative chemoradiotherapy in rectal cancer cases. Asian Pac. J. Cancer Prev. 2013, 14, 3881-3885. [CrossRef]

88. Noh, O.K.; Oh, S.Y.; Kim, Y.B.; Suh, K.W. Prognostic Significance of Lymphocyte Counts in Colon Cancer Patients Treated with FOLFOX Chemotherapy. World J. Surg. 2017, 41, 2898-2905. [CrossRef]

89. Yang, J.; Guo, X.; Wang, M.; Ma, X.; Ye, X.; Lin, P. Pre-treatment inflammatory indexes as predictors of survival and cetuximab efficacy in metastatic colorectal cancer patients with wild-type RAS. Sci. Rep. 2017, 7, 17166. [CrossRef]

90. Proctor, M.J.; Morrison, D.S.; Talwar, D.; Balmer, S.M.; Fletcher, C.D.; O’Reilly, D.S.; Foulis, A.K.; Horgan, P.G.; McMillan, D.C. A comparison of inflammation-based prognostic scores in patients with cancer. A Glasgow Inflammation Outcome Study. Eur. J. Cancer 2011, 47, 2633-2641. [CrossRef]

91. Yamamoto, T.; Kawada, K.; Obama, K. Inflammation-Related Biomarkers for the Prediction of Prognosis in Colorectal Cancer Patients. Int. J. Mol. Sci. 2021, 22, 8002. [CrossRef] [PubMed]

92. Luckheeram, R.V.; Zhou, R.; Verma, A.D.; Xia, B. CD4 ${ }^{+}$T Cells: Differentiation and Functions. Clin. Dev. Immunol. 2012, 2012, 925135. [CrossRef]

93. Apte, R.N.; Voronov, E. Is interleukin-1 a good or bad 'guy' in tumor immunobiology and immunotherapy? Immunol. Rev. 2008, 222, 222-241. [CrossRef] [PubMed]

94. Lin, A.; Zhang, J.; Luo, P. Crosstalk Between the MSI Status and Tumor Microenvironment in Colorectal Cancer. Front. Immunol. 2020, 11, 2039. [CrossRef]

95. Le, D.T.; Durham, J.N.; Smith, K.N.; Wang, H.; Bartlett, B.R.; Aulakh, L.K.; Lu, S.; Kemberling, H.; Wilt, C.; Luber, B.S.; et al. Mismatch repair deficiency predicts response of solid tumors to PD-1 blockade. Science 2017, 357, 409-413. [CrossRef] [PubMed]

96. Lin, A.; Zhang, H.; Hu, X.; Chen, X.; Wu, G.; Luo, P.; Zhang, J. Age, sex, and specific gene mutations affect the effects of immune checkpoint inhibitors in colorectal cancer. Pharmacol. Res. 2020, 159, 105028. [CrossRef] [PubMed]

97. Zhang, J.; Zhou, N.; Lin, A.; Luo, P.; Chen, X.; Deng, H.; Kang, S.; Guo, L.; Zhu, W.; Zhang, J. ZFHX3 mutation as a protective biomarker for immune checkpoint blockade in non-small cell lung cancer. Cancer Immunol. Immunother. 2021, 70, 137-151. [CrossRef]

98. Dinarello, C.A. Biologic basis for interleukin-1 in disease. Blood 1996, 87, 2095-2147. [CrossRef]

99. Tanaka, T.; Narazaki, M.; Kishimoto, T. IL-6 in inflammation, immunity, and disease. Cold Spring Harb. Perspect. Biol. 2014, 6, a016295. [CrossRef] [PubMed]

100. Sun, X.; Feng, R.; Li, Y.; Lin, S.; Zhang, W.; Li, Y.; Sun, C.; Li, S. Histidine supplementation alleviates inflammation in the adipose tissue of high-fat diet-induced obese rats via the NF-кB- and PPAR $\gamma$-involved pathways. Br. J. Nutr. 2014, 112, 477-485. [CrossRef] [PubMed]

101. Samani, A.A.; Yakar, S.; LeRoith, D.; Brodt, P. The role of the IGF system in cancer growth and metastasis: Overview and recent insights. Endocr. Rev. 2007, 28, 20-47. [CrossRef] 
102. Key, T.J.; Appleby, P.N.; Reeves, G.K.; Roddam, A.W. Insulin-like growth factor 1 (IGF1), IGF binding protein 3 (IGFBP3), and breast cancer risk: Pooled individual data analysis of 17 prospective studies. Lancet. Oncol. 2010, 11, 530-542. [PubMed]

103. Nowakowska-Zajdel, E.; Mazurek, U.; Ziółko, E.; Niedworok, E.; Fatyga, E.; Kokot, T.; Muc-Wierzgoń, M. Analysis of expression profile of gene encoding proteins of signal cascades activated by insulin-like growth factors in colorectal cancer. Int J. Immunopathol. Pharmacol. 2011, 24, 781-787. [CrossRef] [PubMed]

104. Walkiewicz, K.; Nowakowska-Zajdel, E.; Kozieł, P.; Muc-Wierzgoń, M. The role of some ADAM-proteins and activation of the insulin growth factor-related pathway in colorectal cancer. Cent. Eur. J. Immunol. 2018, 43, 109-113. [CrossRef] [PubMed]

105. Furuhashi, M.; Hotamisligil, G.S. Fatty acid-binding proteins: Role in metabolic diseases and potential as drug targets. Nat. Rev. Drug Discov. 2008, 7, 489-503. [CrossRef] [PubMed]

106. Furuhashi, M.; Ishimura, S.; Ota, H.; Miura, T. Lipid chaperones and metabolic inflammation. Int. J. Inflam. 2011, $2011,642612$. [CrossRef] [PubMed]

107. Hotamisligil, G.S.; Bernlohr, D.A. Metabolic functions of FABPs-Mechanisms and therapeutic implications. Nat. Rev. Endocrinol. 2015, 11, 592-605. [CrossRef]

108. Zhang, Y.; Zhao, X.; Deng, L.; Li, X.; Wang, G.; Li, Y.; Chen, M. High expression of FABP4 and FABP6 in patients with colorectal cancer. World J. Surg. Oncol. 2019, 17, 171. [CrossRef]

109. Ishimura, S.; Furuhashi, M.; Watanabe, Y.; Hoshina, K.; Fuseya, T.; Mita, T.; Okazaki, Y.; Koyama, M.; Tanaka, M.; Akasaka, H.; et al. Circulating levels of fatty acid-binding protein family and metabolic phenotype in the general population. PLoS ONE 2013, 8, e81318. [CrossRef] 